\title{
Recent Advances in the Application of Ring-Closing Metathesis for the Synthesis of Unsaturated Nitrogen Heterocycles
}

\author{
Emilia J. Groso \\ Corinna S. Schindler* (D) \\ Department of Chemistry, Willard Henry Dow Laboratory, University \\ of Michigan, 930 North University Avenue, Ann Arbor, Michigan \\ 48109, USA \\ corinnas@umich.edu \\ Published as part of the 50 Years SYNTHESIS - Golden Anniversary Issue
}

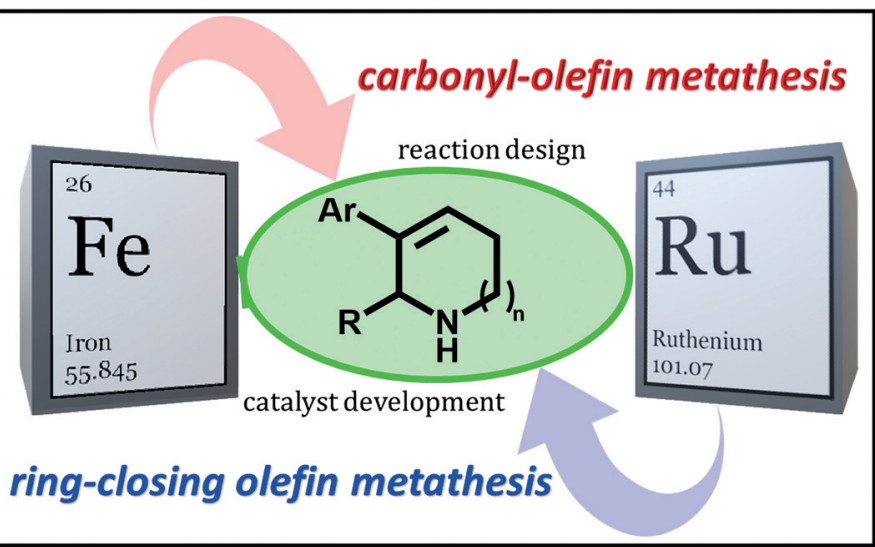

\section{Received: 09.12.2018 \\ Accepted: 14.12 .2018 \\ Published online: 08.02 .2019 \\ DOI: 10.1055/s-0037-1611651; Art ID: ss-2018-z0835-sr \\ License terms: cc)}

Abstract This short review summarizes recent advances relating to the application of ring-closing olefin-olefin and carbonyl-olefin metathesis reactions towards the synthesis of unsaturated five- and six-membered nitrogen heterocycles. These developments include catalyst modifications and reaction designs that will enable access to more complex nitrogen heterocycles.

Introduction

Expansion of Ring-Closing Metathesis Methods

Evaluation of Catalyst Design

Indenylidene Catalysts

Unsymmetrical $\mathrm{N}$-Heterocyclic Carbene Ligands

Carbonyl-Olefin Metathesis

Conclusions

Key words RCM, carbonyl-olefin metathesis, nitrogen heterocycles, catalyst design, ruthenium, Lewis acid catalysis

\section{Introduction}

Nitrogen heterocycles are among the most prevalent structural motifs in both natural and unnatural biologically active compounds. ${ }^{1}$ This ubiquitous scaffold (Figure 1) can be found in pharmaceutically relevant compounds such as iminosugars (1 and 2), ${ }^{2}$ therapeutics (3-5), ${ }^{3}$ and alkaloids $(6-8)^{4}$ as well as chiral ligands ${ }^{5}$ and organocatalysts for asymmetric synthesis. ${ }^{6}$ Due to the overall utility and abundance of nitrogen heterocycles, their syntheses continue to be an active area of interest.

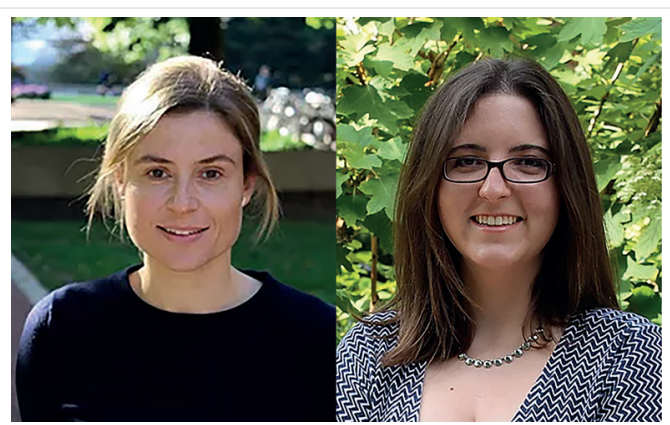

Corinna S. Schindler (left) received her diploma in chemistry from the Technical University of Munich. After a research stay with K. C. Nicolaou at the Scripps Research Institute, she joined the group of Erick Carreira at ETH Zürich for her graduate studies. She then returned to the USA to conduct postdoctoral studies with Eric Jacobsen at Harvard before starting her independent career at the University of Michigan in 2013. Emilia J. Groso (right) was born in Nevada in 1990 and received her B.S. in chemistry from the University of Nevada, Reno under the supervision of Professor Robert S. Sheridan in 2013. She is currently a graduate student at the University of Michigan working with Professor Corinna S. Schindler on the development of new methods towards the synthesis of nitrogen heterocycles.

For the purposes of this review we will focus on the unsaturated five- and six-membered nitrogen heterocycles, specifically 3-pyrrolines and tetrahydropyridines. Such compounds serve as useful synthetic building blocks as the resulting olefin provides a functional handle for further diversification. ${ }^{7}$ There are a variety of strategies to directly access these aza-cycles (Scheme 1). ${ }^{8,9}$ Several cyclization 
strategies have been developed to access 3-pyrrolines, including the cyclization of $\alpha$-amino allenes mediated by transition metals ${ }^{10}$ and potassium carbonate. ${ }^{11}$

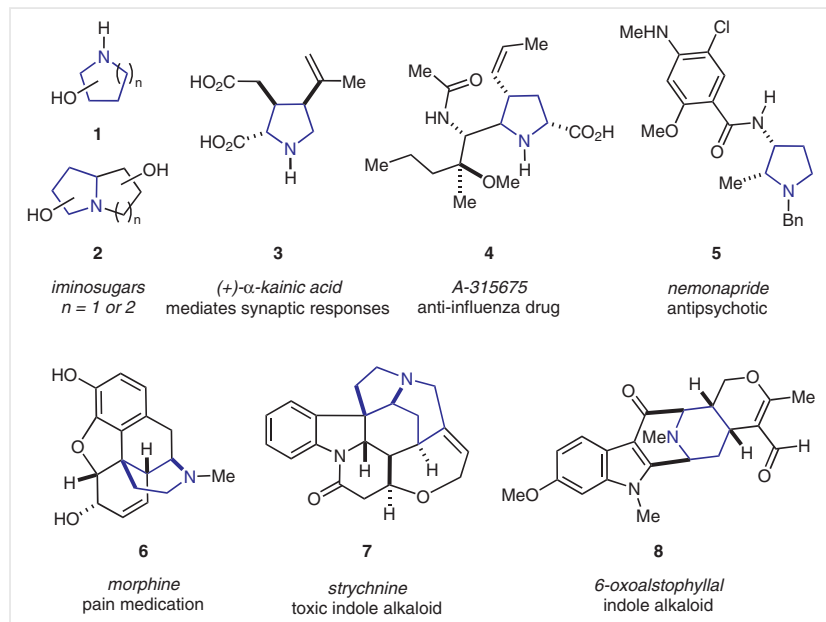

Figure 1 Therapeutics and natural products containing pyrrolidine and piperidine structural motifs

Other cyclization strategies include Heck-aza-Michael reactions, ${ }^{12}$ in situ formation of alkylidene carbenes from vinyl bromides resulting in $1,5-\mathrm{C}-\mathrm{H}$ insertion, ${ }^{13}$ the use of azomethine ylides, ${ }^{14}$ and Lewis acid mediated cyclizations. ${ }^{15}$ Another interesting approach includes the ring expansion of aziridines ${ }^{16}$ to the corresponding pyrroline, or alternatively the ring contraction of diazo-oxazepanes. ${ }^{17}$ Tetrahydropyridines present a greater challenge, however many versatile methods have been developed including $6 \pi-$ cyclization strategies ${ }^{18}$ such as the aza-Diels-Alder reaction $^{19}$ (Scheme 1). Alternative strategies take advantage of traditional amine reactivity including nucleophilic additions to substituted olefins ${ }^{20}$ and phosphine catalysis ${ }^{4 a, 21}$ to promote the cyclization to generate the desired tetrahydropyridines. Finally, similar mechanistic strategies for accessing 3-pyrrolines and tetrahydropyridines have been reported, including allene annulation ${ }^{22}$ and the reduction of the aromatic pyrroles and pyridines. ${ }^{23}$

One strategy that has been proven effective for the synthesis of unsaturated nitrogen heterocycles is ring-closing olefin metathesis. Metal alkylidenes have been implemented in ring-closing metathesis reactions to access both aliphatic and heterocyclic rings, ${ }^{24}$ however electron-rich amines have proven to be challenging substrates under metathesis conditions. The synthesis of aza-cycles via olefinolefin metathesis was initially reported in 1992 by Grubbs and $\mathrm{Fu}^{25}$ who found that subjecting allylamines to a metal alkylidene such as the Grubbs 1st generation catalyst G-I or Schrock's catalyst provided the ring-closing metathesis product in good to excellent yields. As this approach was expanded to more complex amine-containing systems, it

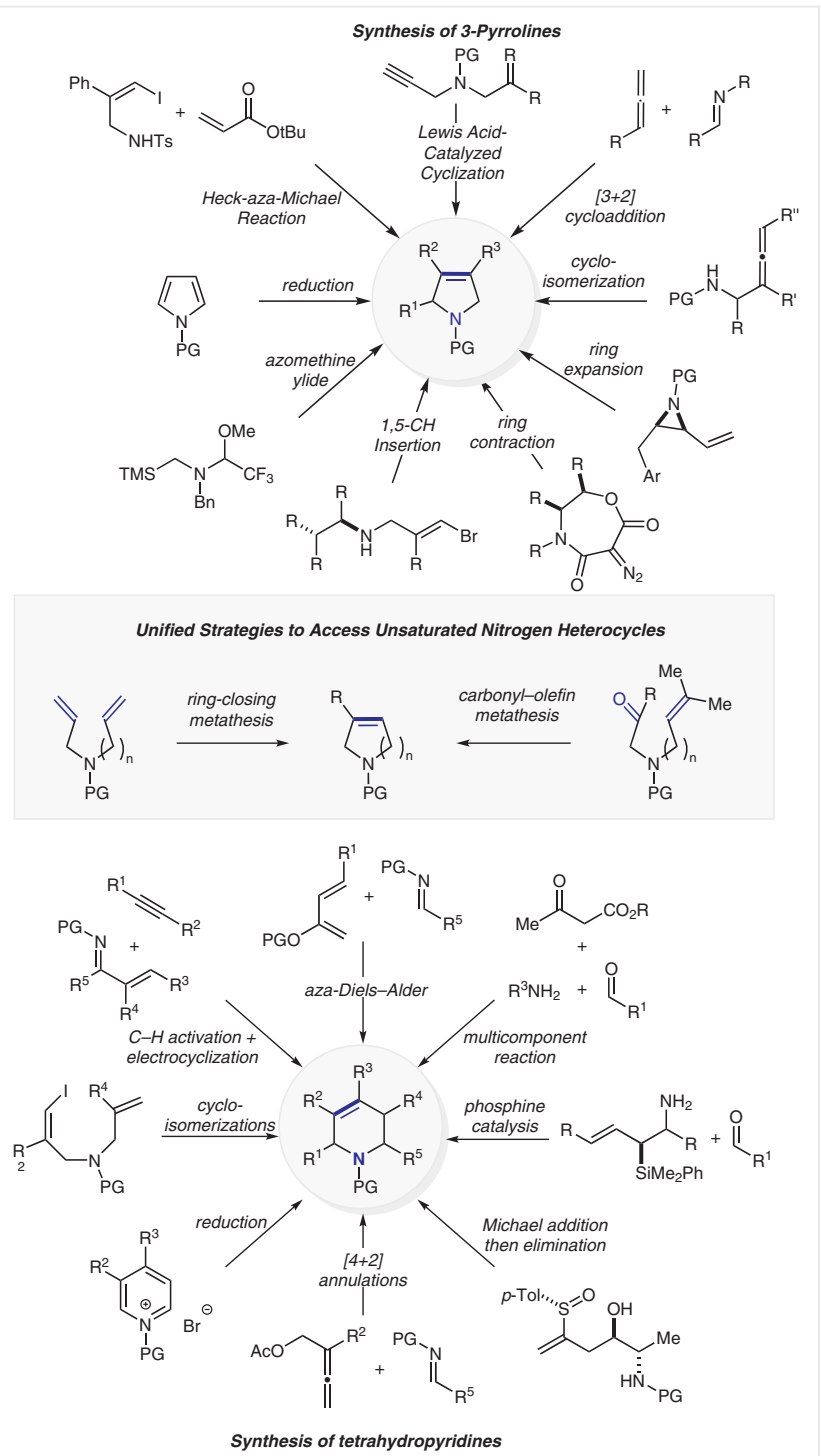

Scheme 1 Summary of synthetic strategies to access unsaturated nitrogen heterocycles

was revealed that the ring-closing metathesis worked well for substituted or electron-deficient amines. However, systems in which amines maintained high electron density were limited due to the decomposition of the catalyst as a result of undesired coordination between the amines and the metal alkylidene complex. ${ }^{26}$

While the presence of Lewis basic amines in metathesis substrates has created a dogma that amines will disrupt the desired reaction, several strategies have emerged that have successfully led to favorable outcomes, including utilizing steric effects, attenuating amine basicity, and controlling the nature of the catalyst itself. There have been several excellent reviews on this topic covering substrate design strategies that have led to the application of ring-closing metathesis to access increasingly complex nitrogen hetero- 
cycles. ${ }^{27}$ This review will instead focus on recent developments in both reaction and catalyst design that have further advanced the field.

\section{Expansion of Ring-Closing Metathesis Methods}

As previously mentioned, amines represent a challenging functional group that can coordinate to metal alkylidenes resulting in catalyst decomposition and ultimately inhibition of the desired olefin metathesis reactions. ${ }^{26} \mathrm{~A}$ variety of strategies have been employed to overcome this inherent shortcoming, including deactivation of the amine by introducing steric bulk to the substrates or by reducing electron-density around the nitrogen atom. With these solutions available, ring-closing metathesis has been applied successfully towards the synthesis of complex nitrogen heterocycles with lower catalyst loadings and shorter reaction times.

Since olefin metathesis was first leveraged for the synthesis of heterocyclic amines, ruthenium catalysts and the understanding of the reaction mechanism have enabled the ring-closing metathesis reaction of unsubstituted diallylamine $\mathbf{9}$ in good yields with low catalyst loadings (Scheme 2a). ${ }^{34}$ Yields continue to rise as the ruthenium-phosphine ligands were replaced with $\mathrm{N}$-heterocyclic carbenes as in the Hoveyda-Grubbs 2 nd generation catalyst HG-II. ${ }^{28} \mathrm{How}-$ ever, while these homogeneous catalysts have been employed in a variety of systems, one challenge, particularly on an industrial scale, is the high catalyst cost and the removal of residual ruthenium after the reaction is complete. As such there has been a continued effort to realize lower catalyst loadings. ${ }^{29,30}$ In 2010, Pederson and co-workers ${ }^{30}$ employed high throughput robotic techniques using Symyx technology in order to identify the optimum reaction conditions for accessing five-, six-, and seven-membered nitrogen heterocycles (Scheme 2b). With this technology, Pederson found that by extending the reaction times to $8 \mathrm{~h}$, the catalyst loading could be lowered to as little as $500 \mathrm{ppm}$ to generate the cyclic amines $\mathbf{1 0}$ and $\mathbf{1 2}$ in as high as 99\% yield (Scheme 2b). The approach also worked well for di-, tri-, and tetrasubstituted olefins.

Another hurdle that has been surpassed in recent years was the application of ring-closing metathesis to access cyclic alkenyl halides which represent valuable synthons. The first reported examples of utilizing ring-closing metathesis for the synthesis of vinyl halides came from Weinreb and co-workers, ${ }^{31}$ who were able to access cyclic chloroalkenes in good yields; however the method did not work for the synthesis of the more synthetically useful vinyl bromides. ${ }^{32}$

In 2010, Dorta and co-workers ${ }^{33}$ reported the first example of the synthesis of cyclic alkenyl bromides by replacing unsubstituted olefins with the styrene derivatives (Schemes 3 and 4). They propose that the terminal olefin

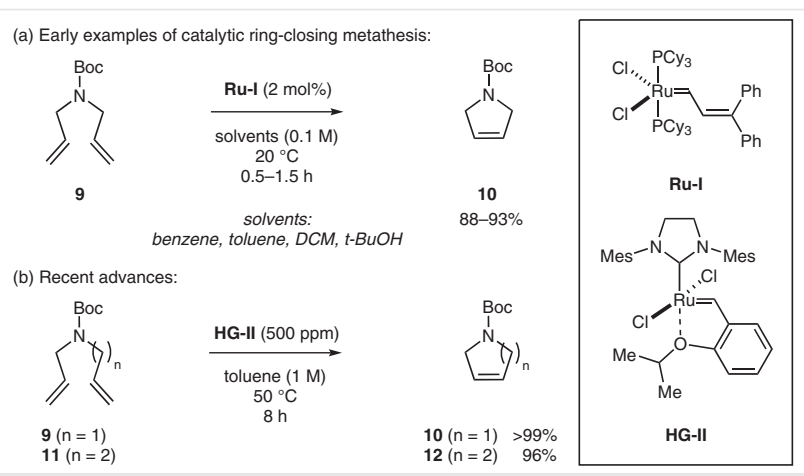

Scheme 2 Recent advances in the application of catalytic ring-closing metathesis towards the synthesis of nitrogen heterocycles

13a undergoes initiation with G-II to generate intermediate 14a. The bromoalkene can then react with the Ru center leading to undesired catalyst decomposition. During examination of the bromoalkene, they found that while the unsubstituted 13a and (E)-styrene 13b both led to complete decomposition of the catalyst (Scheme 3, entries 1 and 2), the $(Z)$-styrene provided the desired product in just 30 minutes with greater than $98 \%$ yield (Scheme 3 , entry 3 ).

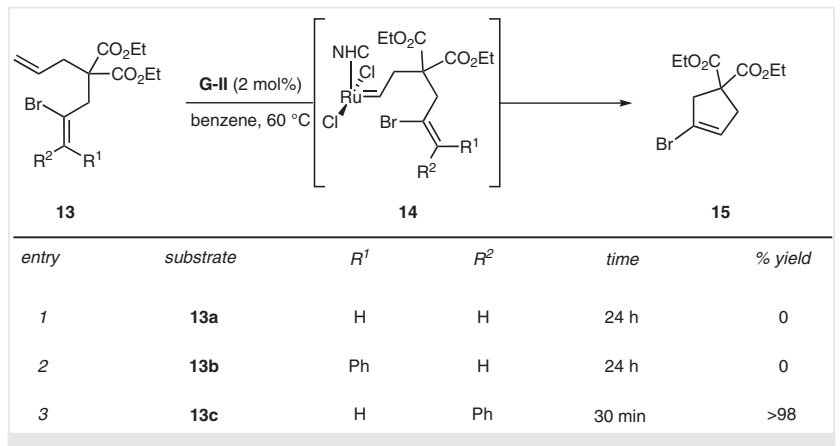

Scheme 3 Investigations into the olefin subunit for the synthesis of cyclic alkenyl bromides; all reactions were performed in $0.1 \mathrm{M}$ benzene. Yields are based on NMR analysis.

This method was also applied towards tosyl-protected amines to access pyrroles and tetrahydropyridines (Scheme 4 ). The reaction worked well for both unsubstituted substrates 16 and 18. Higher yields (up to 97\%) were observed upon incorporation of a phenyl substituent adjacent to the amine in 17, 19, and $\mathbf{2 0}$. The method was also surprisingly facile and led to the synthesis of tetrasubstituted cyclic chloroalkene 21.

While this strategy focused on substrate modification, many approaches have targeted ways to reduce the electron-density around the amine without the introduction of additional functional groups or steps. One such approach involves the in situ protection of amines via the formation of amine salts in order to prevent catalyst decomposition (Scheme 5). Similar deactivation strategies have been em- 


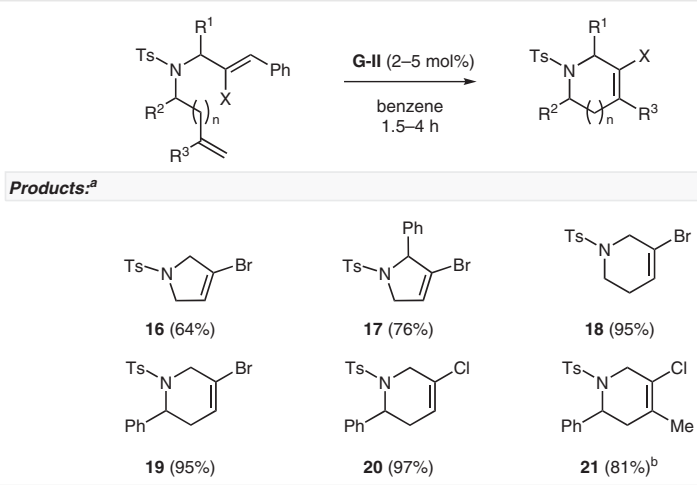

Scheme 4 Catalytic ring-closing metathesis towards the synthesis of cyclic alkenyl halides. ${ }^{a}$ Substrate $(0.16 \mathrm{mmol}), \mathrm{G}-\mathrm{II}(2 \mathrm{~mol} \%), 0.1 \mathrm{M}$ benzene, $1.5-2$ h. ${ }^{\text {b }}$ G-II (5 mol\%), DCM, 4 h.

ployed performing the in situ deactivation of amines via the addition of Brønsted ${ }^{34,26 \mathrm{~h}}$ or Lewis acids. ${ }^{35}$ This approach was successfully utilized in 2011 by Robinson and co-work$\mathrm{ers}^{36}$ to generate both cyclic and acyclic aminoalkenes. Initially, the approach was hindered by the solubility of the amine salts in organic solvents. After examining a variety of amine salts including halide, triflate, and tetrafluoroborate salts, the amine tosylate salts such as $\mathbf{2 2}$ and $\mathbf{2 4}$ were identified as superior substrates due to their solubility in dichloromethane at elevated temperatures. The amine tosylate salts were subjected to ring-closing metathesis under

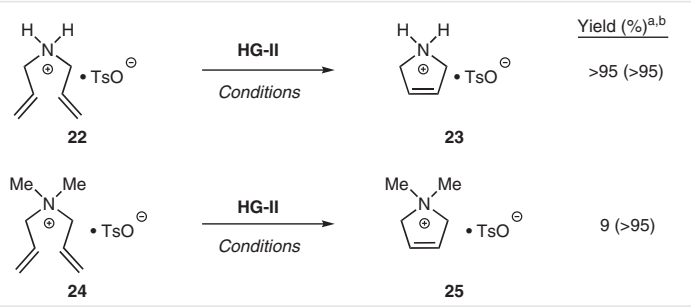

Scheme 5 Methods: a Conventional method: HG-II (5 mol\%), $0.1 \mathrm{M}$ $\mathrm{DCM}, 40{ }^{\circ} \mathrm{C}, 24 \mathrm{~h}$. ${ }^{\mathrm{b}}$ Microwave conditions (yield in parentheses): HG-II ( $5 \mathrm{~mol} \%$ ), $0.1 \mathrm{M} \mathrm{DCM}, 2 \mathrm{~h}, 100 \mathrm{~W}$, under $\mathrm{N}_{2}$. All yields determined by ${ }^{1} \mathrm{H}$ NMR spectroscopy in $\mathrm{CD}_{3} \mathrm{OD}$. both conventional and microwave heating conditions. While the ammonium salt $\mathbf{2 2}$ gave excellent yields of pyrroline $\mathbf{2 3}$ under both conditions, the quaternary amine $\mathbf{2 4}$ resulted in low conversion under conventional methods, but on microwave irradiation pyrroline $\mathbf{2 5}$ was obtained in excellent yield (Scheme 5). Furthermore, this approach is desirable since the resulting product $\mathbf{2 3}$ could be readily deprotected under basic conditions without further chemical modifications.

Another advance in the metathesis-mediated formation of nitrogen heterocycles is the strategic implementation of this synthetic tool to access highly desired chiral nitrogen heterocycles. ${ }^{37}$ One such example came from Feringa and co-workers, ${ }^{38}$ who developed a copper-catalyzed method for the asymmetric substitution of allylic bromides with Grignard reagents through the use of chiral ferrocene-based bisphosphine ligands L1. Recognizing that this method produced terminal olefins, they utilized it to convert the allyl bromides 26 and 29 into the chiral olefin metathesis substrate $\mathbf{2 7}$ and chiral ene-yne metathesis substrate 30, which were then subjected to metathesis conditions to obtain access to enantioenriched products $\mathbf{2 8}$ and $\mathbf{3 1}$, respectively (Scheme 6). Thus allylic bromides provided chiral tetrahydropyridines in good yields and complete stereoretention. Additionally, this method was applicable for the synthesis of seven- and eight-membered rings.

\section{Evaluation of Catalyst Design}

While the discussion in Section 2 focused on modifications in the reaction design and conditions to promote the desired ring-closing metathesis, another key strategy employs changes in catalyst design. Significant advances in metathesis reactions have been realized as a result of the development of more robust and highly reactive ruthenium catalysts that promote ring-closing metathesis without unfavorable side reactions. Specifically, modifications on the benzylidene ligands have resulted in significant changes in steric strain, chelate ring size, and electron density of the aromatic ring. Two such examples of major modifications in

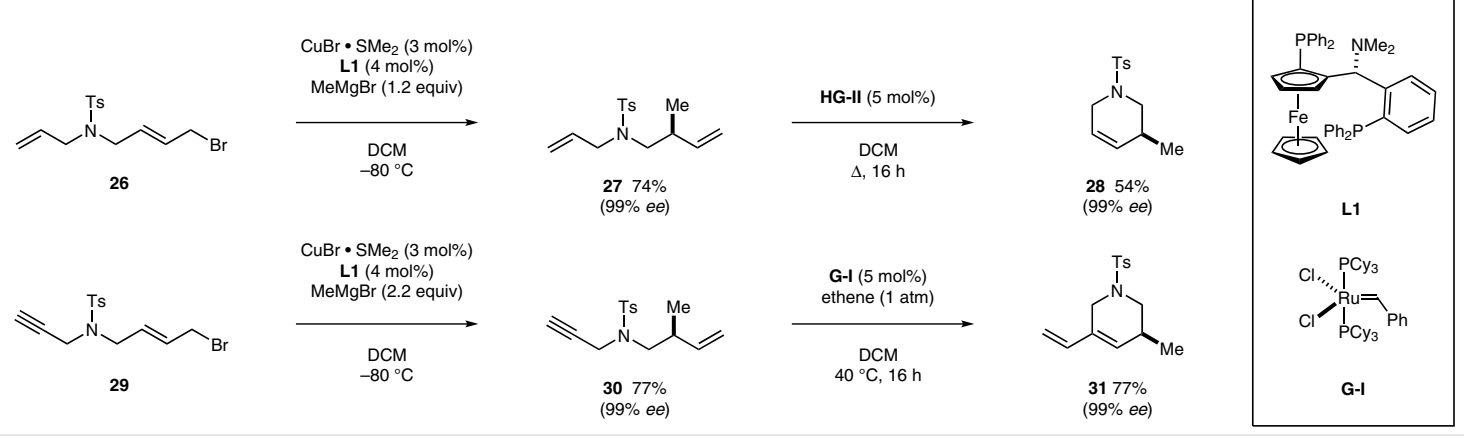

Scheme 6 Asymmetric allylic alkylation and subsequent RCM for the preparation of chiral tetrahydropyridines 
(a) Modified HG-II catalysts investigated
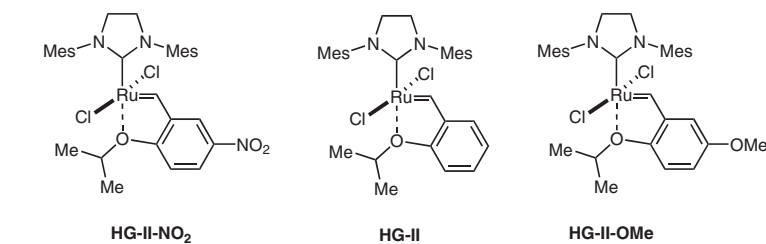

HG-II

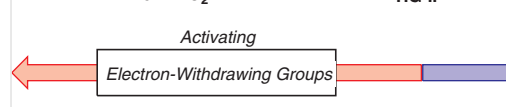

HG-II-OMe

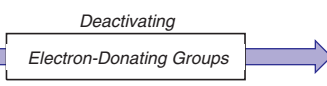

(c) Electronic effects on Hoveyda-Grubbs catalysts

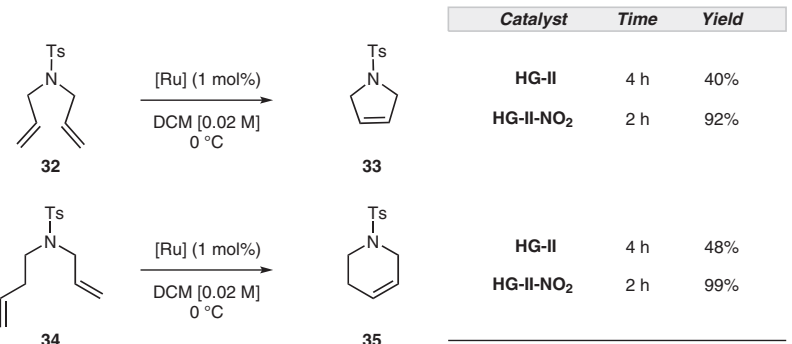

34

Scheme 7 Role of electronics on benzylidene catalyst design ${ }^{40,41}$

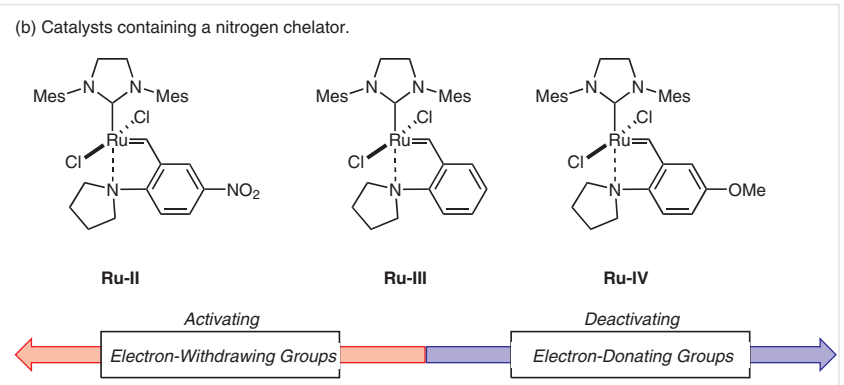

(d) Electronic effects with chelating nitrogen
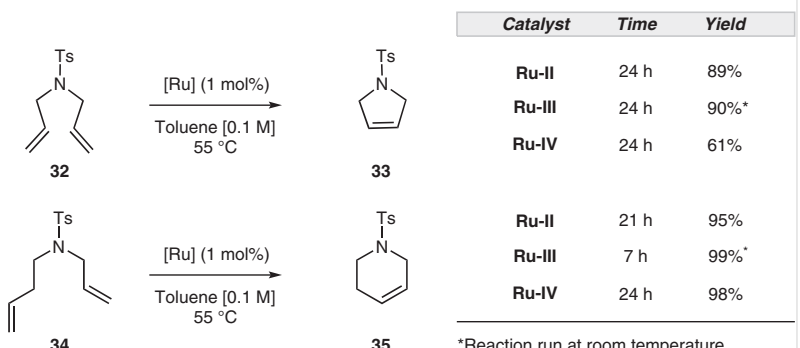

*Reaction run at room temperature. ligand design have been the replacement of a tricyclohexylphosphine ligand in $\mathbf{G}-\mathbf{I}$ with a more active $\mathrm{N}$-heterocyclic carbene to give $\mathbf{G}-\mathbf{I I}^{28}$ and the incorporation of benzylidene ligands to give HG-II. ${ }^{39}$

Continued studies of ligand development and design reveal that the electronic substitution of the ligand also plays a critical role in catalyst reactivity and stability (Scheme 7). ${ }^{40}$ For instance, the reactivity of HG-II can be significantly enhanced by the addition of an electron-withdrawing substituent such as the nitro group in HG-II-NO $\mathbf{N}_{2}$ which diminishes the donor activity of the oxygen chelate (Scheme 7c).

In 2010, Grela, Lemcoff, and co-workers ${ }^{41}$ undertook a variety of studies exploring electronic effects in ruthenium catalysts containing oxygen-, nitrogen-, and sulfur-chelated ligands. Changing the chelating heteroatom had a significant impact on the reactivity of the catalyst and its ability to undergo initiation. The electron-rich nitrogen (Ru-II, RuIII, and Ru-IV, Scheme 7b) and sulfur derivatives required elevated temperatures and longer reaction times (Scheme 7d) to give yields comparable to those obtained with HG-II and HG-II-NO $\mathbf{O}_{2}$ (Scheme 7c). However, while these catalysts were relatively slow to initiate, addition of the nitro group greatly affected the overall stability of the catalyst and its ability to mediate the ring-closing metathesis of allylamines 32 and 34. Comparison of $\mathbf{3 2}$ and $\mathbf{3 4}$ revealed that while catalysts Ru-II and Ru-IV both required elevated temperature of $55{ }^{\circ} \mathrm{C}$, the substrate could be subjected to Ru-III at room temperature to provide products 33 and 35 in excellent yield.

When the ligand was altered to contain an electron-rich benzylidene ring as in $\mathbf{R u}-\mathbf{I V}$, the yield of $\mathbf{3 3}$ decreased to $61 \%$ (Scheme 7d). A similar trend was observed in the syn- thesis of tetrahydropyridine 35. Use of electron-rich catalyst Ru-IV required elevated temperatures and longer reaction times, whereas the electron-deficient catalyst Ru-III gave similar yields at room temperature in only 7 hours.

The chelating heteroatom can also play a significant role in the catalyst stability. While most metal alkylidene catalysts perform well at room temperature or slightly elevated temperatures, some selected applications require that the catalyst has high thermal stability. For example, the latent catalyst is activated, the methylidene species can rapidly form in solution. At higher temperatures, decomposition of the metal alkylidene is proven to lead to the formation of ruthenium hydride species that can result in the isomerization of olefinic bonds and the formation of byproducts such as 36 (Scheme 8 ). ${ }^{42}$

Ligands with a strongly coordinating heteroatom chelator such as oxygen, ${ }^{43}$ nitrogen, ${ }^{44}$ sulfur, ${ }^{45}$ and selenium ${ }^{46}$ provide greater thermal stability. For instance, Slugove and co-workers ${ }^{47}$ began exploring the use of ruthenium alkylidene catalysts bearing a chelating phosphine ligand $\mathbf{R u}-$ V for both ring-opening metathesis polymerization and ring-closing metathesis (Scheme 8). When this catalyst was used for the synthesis of pyrroline 33, it provided the desired product in $>97 \%$ yield with reaction temperatures as high as $110{ }^{\circ} \mathrm{C}$. They also found that the catalyst $\mathbf{R u}-\mathbf{V}$ could provide good yields of the product at lower temperatures when the solvent was switched to chloroform. At both elevated and lower temperatures, some traces of the isomerized product $\mathbf{3 6}$ were observed, but this could further be avoided by the introduction of a hydride scavenger such as benzoquinone (Scheme 8 , entry 6 ). 


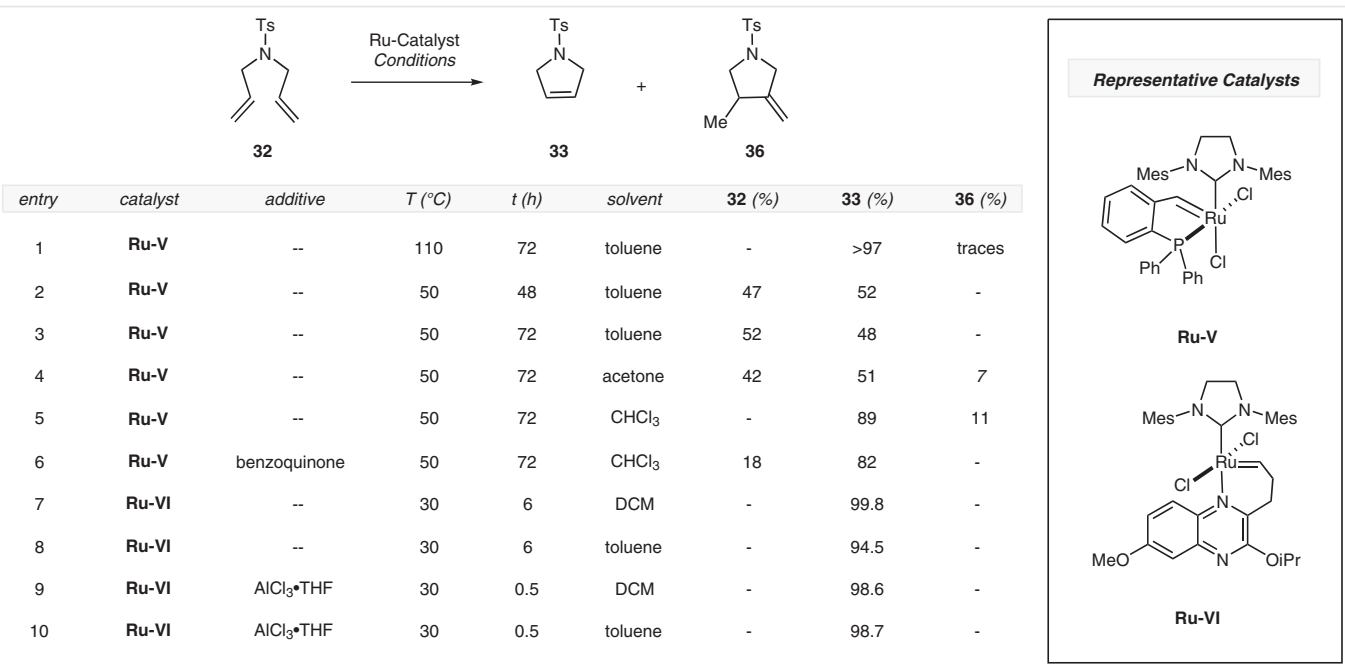

Scheme 8 Role of chelating ligands, solvents and additives in ring closing metathesis ${ }^{47,49}$

While the phosphine chelator provides increased stability of the active methylidene species at elevated temperatures, another continued goal is accessing a tunable, shelfstable catalyst. Such a catalyst was serendipitously discovered by Williams, Kong and co-workers in 2016 during the synthesis of the macrocyclic backbone of the HCV therapeutic agent grazoprevir ${ }^{48}$ (MK-5172, 37) from 38 via ringclosing metathesis using HG-II (Scheme 9); ${ }^{49}$ the first quinoxaline Ru-VI (Scheme 8) was isolated as a byproduct of the metathesis reaction. Quinoxaline Ru-VI was found to be stable in deuterated dichloromethane for up to 30 days, while the neat catalyst demonstrated shelf stability of up to 6 months. This stability is likely due the steric repulsion between the quinoxaline and the mesitylene rings preventing the rearrangement to the inactive cis isomer of the catalyst. ${ }^{49}$
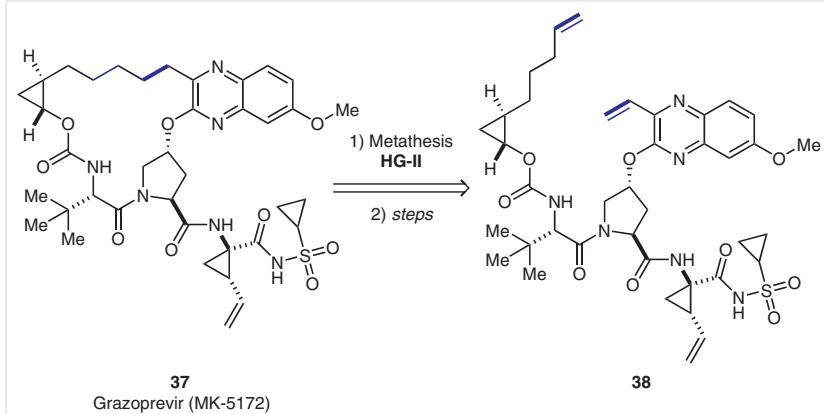

Scheme 9 Retrosynthetic strategy towards the synthesis of grazoprevir via an olefin ring-closing metathesis and subsequent reduction

The effectiveness of the catalyst Ru-VI was tested against allylamine $\mathbf{3 2}$ to access pyrroline 33. Catalyst Ru-VI gave complete conversion of sulfonamide 32 in 6 hours and $99 \%$ yield (Scheme 8, entry 7). Considering that electron- deficient catalysts are more active in ring-closing metathesis reactions, they proposed ${ }^{49}$ that the reaction rate could be increased through the protonation of the quinoxaline ligand with an acid catalyst. After examining both Brønsted and Lewis acids, $\mathrm{AlCl}_{3}$ was found to give complete conversion and excellent yields of $\mathbf{3 3}$ in only $\mathbf{3 0}$ minutes (Scheme 8 , entries 9 and 10). ${ }^{49}$

As previously discussed, the decomposition of the active methylidene species in solution to ruthenium hydrides results in undesired isomerization of the olefins. ${ }^{42}$ While hydride scavengers such as quinones, acids, and chlorocatecholborane have proven effective in the prevention of undesired pathways, they do not necessarily prevent catalyst decomposition. Kajetanowicz and co-workers ${ }^{50}$ envisioned incorporating the quinone moiety into the catalyst struc-

(a) Incorporation of quinone moiety for the prevention of olefin isomerization

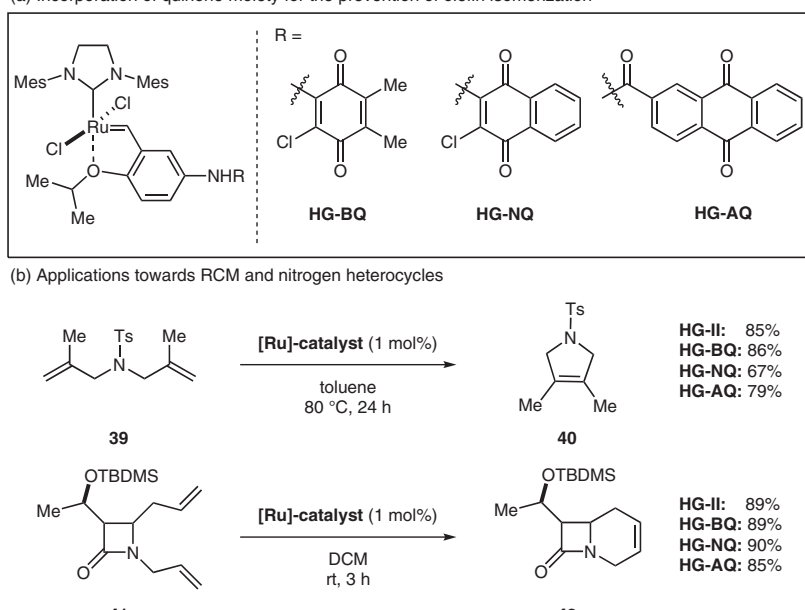

41

42

Scheme 10 Comparison of Hoveyda-Grubbs derivatives containing a quinone moiety with Hoveyda-Grubbs 2 nd generation catalyst ${ }^{50}$ 


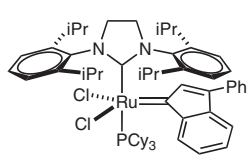

Ru-VII

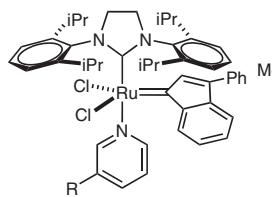

Ru-VIII $(R=H)$

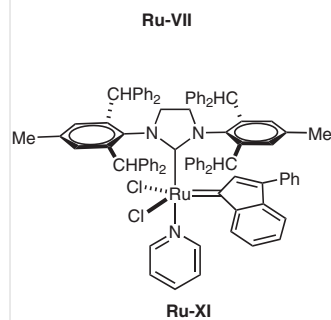

Ru-IX $(\mathrm{R}=\mathrm{Br})$
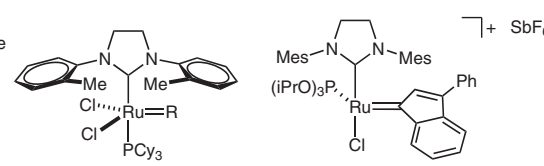

Ru-XII ( $\mathrm{R}=$ benzylidene) Ru-XIII ( $R=$ indenylidene $)$

$\operatorname{caz}^{+} 1^{+}$

(b) Analysis of the role of sterics on the synthesis of 1-tosyl-2,5-dihydro-1 1 -pyrrole:
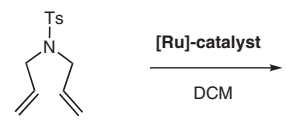

32

\begin{tabular}{|ccc|}
\hline entry & catalyst & loading \\
1 & Ru-VII & $100 \mathrm{ppm}$ \\
2 & Ru-VIII & $100 \mathrm{ppm}$ \\
3 & Ru-IX & $100 \mathrm{ppm}$ \\
4 & Ru-VII & $1 \mathrm{~mol} \%$ \\
5 & Ru-VIII & $1 \mathrm{~mol} \%$ \\
6 & Ru-X & $1 \mathrm{~mol} \%$ \\
7 & Ru-XI & $1 \mathrm{~mol} \%$
\end{tabular}

th) concentration (M) conversion $(\%)$

0.5

0.5

0.5

0.1

0.1

0.1

0.1

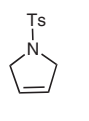

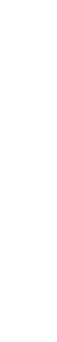

50
76
88
$>99$
$>99$
$>99$
96

Scheme 11 Studies into indenylidene catalysts. ${ }^{\mathrm{a}} 0.1 \mathrm{M} \mathrm{DCM}, \mathrm{rt}^{\mathrm{b}}{ }^{\mathrm{b}} 0.1 \mathrm{M}$ toluene, $60^{\circ} \mathrm{C} . \mathrm{c}^{\mathrm{c}} 0.25 \mathrm{M}$ xylene, $140{ }^{\circ} \mathrm{C} .{ }^{55,56,59,61}$

ture, and synthesized the Hoveyda-Grubbs derivatives with benzoquinone HG-BQ naphthoquinone HG-NQ and anthraquinone moieties HG-AQ. These catalysts were tested and compared to HG-II for the metathesis of tosylamide $\mathbf{3 9}$ and lactam 41 (Scheme 10). The benzoquinone catalyst gave comparable yields to HG-II demonstrating that there is no loss in reactivity of the catalyst. These catalysts were also tested for their ability to prevent olefin isomerization by gauging their ability to selectively perform the homodimerization of dodec-1-ene. While HG-II performed the metathesis reaction in $69 \%$ conversion, it only had a selectivity of 70\%. However, HG-BQ and HG-NQ were able to complete the reaction in $89 \%$ and $94 \%$ conversion, respectively; not only did these catalysts outperform HG-II, but they both formed the desired product with $95 \%$ selectivity. (c) Application of indenylidenes towards the synthesis of nitrogen heterocycles:

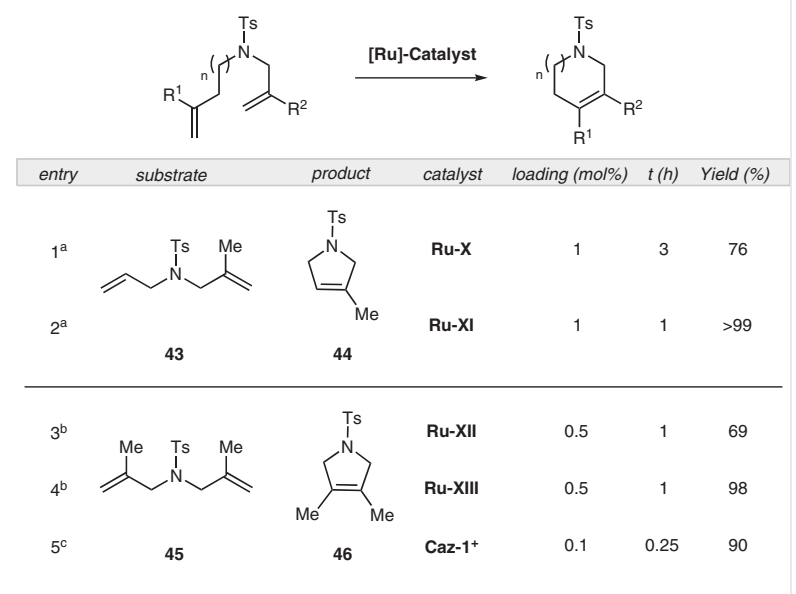

\begin{tabular}{|c|c|c|c|c|c|c|}
\hline entry & substrate & product & catalyst & loading (mol\%) & $t(h)$ & Yield (\%) \\
\hline $1^{a}$ & & & Ru-X & 1 & 3 & 76 \\
\hline $2^{\mathrm{a}}$ & & & Ru-XI & 1 & 1 & $>99$ \\
\hline $3^{\mathrm{b}}$ & & & Ru-XII & 0.5 & 1 & 69 \\
\hline $4^{\mathrm{b}}$ & & & Ru-XIII & 0.5 & 1 & 98 \\
\hline $5^{c}$ & 45 & 46 & $\mathrm{Caz}_{-1}{ }^{+}$ & 0.1 & 0.25 & 90 \\
\hline
\end{tabular}

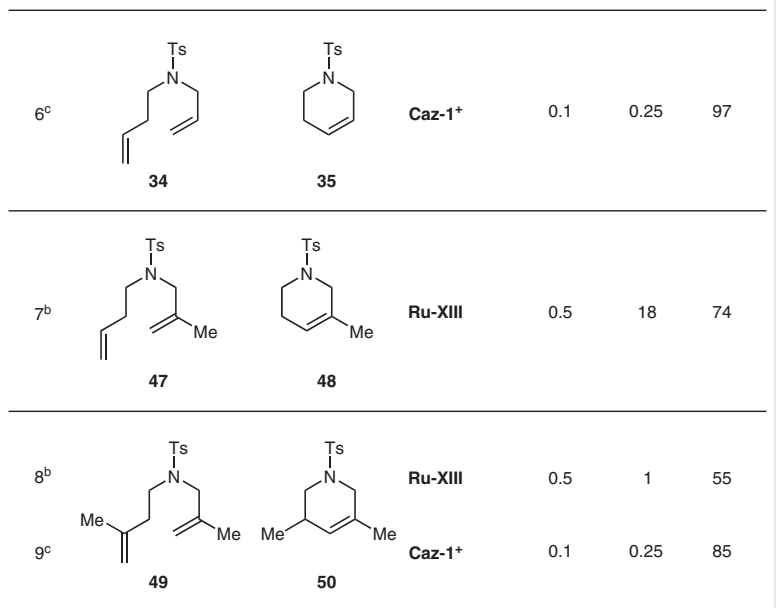

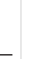


In 2011, Nolan and co-workers reported the synthesis of indenylidene catalysts Ru-VIII and Ru-IX (Scheme 11) and explored their reactivity and steric effects in ring-closing, enyne, and cross-metathesis reactions. ${ }^{55}$ When tested against the diallylamine $\mathbf{3 2}$, the pyridine ligands outperformed the phosphine derivatives by up to $30 \%$ with catalyst loadings as low as $100 \mathrm{ppm}$ (Scheme 11b, entries $1-3) .{ }^{55}$ The reaction also worked exceedingly well with the more substituted prenylamine 43 ; however, higher catalyst loadings of $250 \mathrm{ppm}$ were required due to the increase in steric bulk around the olefin. ${ }^{55}$

In 2012, Nolan and co-workers expanded their studies on indenylidene catalysts and synthesized catalysts Ru-XI, Ru-XII, and Ru-XIII. ${ }^{56}$ For the unsubstituted diallylamine 32, all the catalysts were able to provide the metathesis product 33 in excellent yields, however, a significant difference in reactivity between the more substituted catalysts was observed. The NHC ligands bearing increased steric bulk required longer reaction times of 3 hours (Scheme 11b, entries 6 and 7). Comparing catalyst Ru-VII and RuVIII, the catalyst containing the pyridine ligand, Ru-VIII, was more reactive than the phosphine, Ru-VII. The reaction went to completion in 30 minutes with Ru-VII, while the reaction with Ru-VIII was completed in 15 minutes (Scheme 11b, entries 4 and 5, respectively). ${ }^{56}$ When the amine bearing the substituted olefin $\mathbf{4 3}$ was subjected to metathesis conditions with catalyst $\mathbf{R u}-\mathbf{X}$, the reaction required 3 hours and only resulted in $76 \%$ conversion of the starting material. This may be due to unfavorable steric interactions of the catalyst that slows down the reaction, but when the phosphine was replaced with the pyridine analogue Ru-XI, the reaction proceeded in $>99 \%$ conversion in just 1 hour (Scheme 11c, entries 1 and 2). The reaction also resulted in excellent yields of the pyrroline $\mathbf{4 4}$, while the more reactive analogue gave a slightly diminished yield. ${ }^{56}$

Because less sterically encumbered NHC ligands such as Ru-VIII tend to be more reactive, albeit less stable overall, there have been significant efforts made to improve their general stability to make them more productive for catalysis. One factor that contributes to the decomposition of the less substituted (and more reactive) indenylidene catalysts is due to increased rotation around the aryl C-N bond. ${ }^{57}$ In an effort to prevent this rotation, one strategy to increase stability is to add alkyl substituents to the backbone, ${ }^{58}$ as illustrated in Ru-XI; however, bulky substituents are also known to lead to reaction inhibition. A viable alternative is to replace the benzylidene in Ru-XII with the more stable indenylidene in Ru-XIII. ${ }^{59}$ When this catalyst Ru-XIII was used to promote the ring-closing metathesis of substituted olefin 45 (Scheme 11c, entries 3 and 4), it out performed its benzylidene counterpart resulting in $98 \%$ of the desired product. The catalyst Ru-XIII was also applied towards the synthesis of substituted tetrahydropyridines $\mathbf{4 8}$ and $\mathbf{5 0}$, albeit with longer reaction times and in diminished yields.
Another new and exciting field is the conversion of the neutral NHC catalysts into their corresponding cationic derivatives. Only a handful of groups have developed systems that utilize cationic catalysts in ring-closing metathesis, but the catalysts can be a powerful tool for accessing challenging metathesis products. ${ }^{60}$ A example from 2012 comes from Cazin and co-workers ${ }^{61 a}$ with the synthesis of cationic catalyst $\mathbf{C a z}-\mathbf{1}^{+}$with a phosphite ligand. Interestingly, similarly reported cationic ruthenium species which are 14 electron complexes tend to dimerize to the more stable 16 electron species. ${ }^{61 b}$ In the case of cationic species $\mathbf{C a z}^{-\mathbf{1}^{+}}$, no dimerization is observed due to the formation of an unusual sawhorse geometry. This makes the catalyst especially stable in solution. While studying ability of the catalyst Caz-1 ${ }^{+}$to convert tosylamine 45 into the pyrroline 46 compared to G-II and HG-II at $140{ }^{\circ} \mathrm{C}$, G-II and HG-II both displayed rapid decomposition and gave only $40 \%$ conversion of the tosylamine. Interestingly, Caz-1 ${ }^{+}$displayed higher thermal stability and reached $90 \%$ conversion after only 10 minutes (Scheme 11c, entry 5). This catalyst was used to access other challenging substrates including tetrahydropyridines $\mathbf{3 5}$ and $\mathbf{5 0}$ in $\mathbf{9 7 \%}$ and $\mathbf{8 5 \%}$ yield, respectively (Scheme 11c, entries 6 and 9).

\section{Unsymmetrical $\mathrm{N}$-Heterocyclic Carbene Ligands}

While NHC ligands have led to a new generation of metal alkylidene catalysts that enable access to new, more complex structures, an ongoing challenge in ring-closing metathesis reactions is performing them asymmetrically to access enantioenriched products. ${ }^{62}$ While asymmetric olefin metathesis reactions have been successfully employed in ring-opening cross metathesis, controlling the olefin geometry continues to be a challenge in asymmetric ring-closing metathesis. Key strategies for applying ring-closing metathesis are through the kinetic resolution of dienes or the desymmetrization of meso-trienes, particularly when the unique olefin is less bulky than the enantiotopic olefins. ${ }^{63}$ Asymmetric ring closing metathesis has been successfully applied to a variety of systems using molybdenum alkylidene catalysts. ${ }^{64}$ Specifically, Schrock, Hoveyda, and Dolman utilized chiral molybdenum-based catalysts such as Mo-I and Mo-II to access cyclic six-, seven-, and eightmembered rings and bicyclic amines in good yields with up to $98 \%$ ee. (Scheme 12 ). ${ }^{65}$

Grubbs and co-workers ${ }^{66}$ postulated that for prochiral trienes to procede in an enantioselective metathesis reaction, one of two possible pathways most occur. The first pathway consists of initial, irreversible alkylidene formation on one of the enantiotopic olefins followed by cyclization with the unique olefin. The second pathway consists of the initial alkylidene formation occurring with the unique 


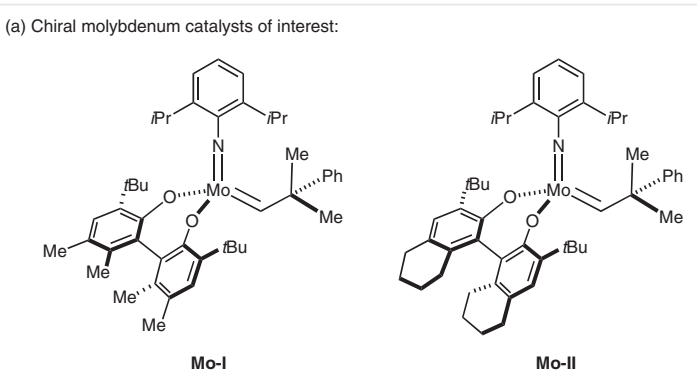

(b) Application of Mo-I and Mo-Il towards tetrahydropyridines:
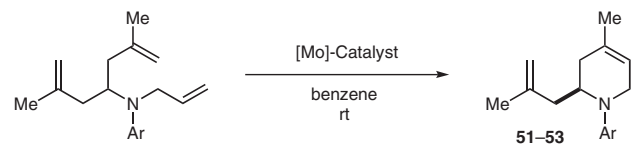

\begin{tabular}{ccccccc}
\hline entry & Ar & & catalyst & time $(h)$ & conversion (\%) & ee (\%) \\
\hline 1 & $\mathrm{Ph}$ & $\mathbf{5 1}$ & Mo-I & 0.3 & 95 & 98 \\
2 & $\mathrm{Ph}$ & $\mathbf{5 1}$ & Mo-II & 1 & 95 & 94 \\
3 & $p-\mathrm{MeOC}_{6} \mathrm{H}_{4}$ & $\mathbf{5 2}$ & Mo-I & 0.35 & 97 & 97 \\
4 & $p-\mathrm{BrC}_{6} \mathrm{H}_{4}$ & $\mathbf{5 3}$ & Mo-I & 0.35 & $>98$ & 98
\end{tabular}

Scheme 12 Chiral molybdenum catalysts in the synthesis of enantioenriched tetrahydropyridines

olefin followed by subsequent cyclization with one of the two enantiotopic olefins. Cavallo and Costabile ${ }^{67}$ performed computational studies on the origin of stereoselectivity and found that the non-reacting olefin is oriented in pseudoequatorial and pseudo-axial positions in the respective diastereomeric transition states for cyclization. With larger substituents, higher selectivities are expected due to the large energy difference between the two configurations. Grubbs and co-workers ${ }^{66}$ hypothesized that utilizing adamantyl catalyst Ru-XIV would promote alkylidene formation with the unique olefin (Figure 2). The utility of this catalyst was first probed against tosylamine 54, and the reaction gave good yields of the pyrroline $\mathbf{5 5}$ with modest enantioselectivity. The reaction also works well with tosylamine $\mathbf{5 6}$ providing the tetrahydropyridine product $\mathbf{5 7}$ with similar yield and slightly higher ee. It is proposed that the stereoinduction is due to the possible transition state in which the vinyl groups are in the pseudo-equatorial position.

Unsymmetrical NHC catalysts are also of interest for addressing the challenge of achieving high selectivity in certain metathesis reactions. Such complexes as demonstrated in the previous example (Figure 2) can significantly alter the stability of key intermediates thus introducing the ability to control the reaction outcome. In order to expand this class of catalyst, Grisi and co-workers ${ }^{68,69}$ set out to identify new ways to enhance the stability of the unsymmetrical NHC catalysts by introducing substituents to the ligand backbone. In particular, syn- and anti-complexes Ru-XV and $\mathbf{R u}-\mathbf{X V I}$ were synthesized, as well as catalysts contain-

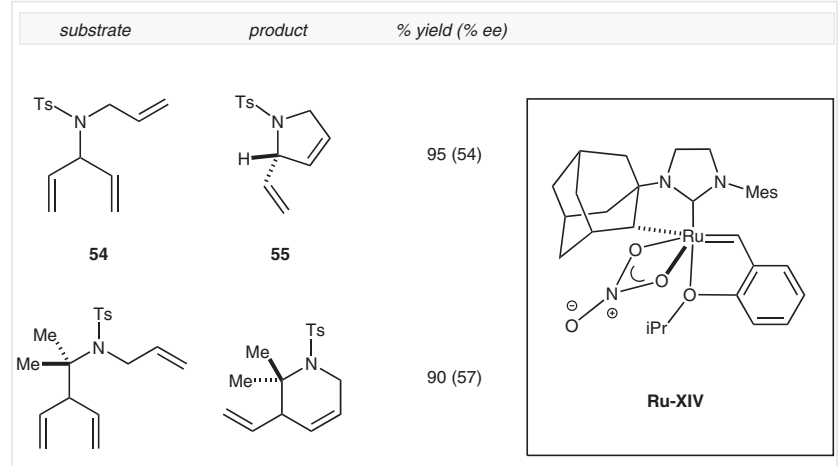

56

57

Figure 2 Application of adamantyl-containing ruthenium catalyst towards the synthesis of chiral pyrrolines and tetrahydropyridines. Reagents and conditions: $\mathbf{R u - X I V ~ ( 5 ~ m o l \% ) , ~ 0 . 5 ~ M ~ T H F , ~} 23^{\circ} \mathrm{C}, 24 \mathrm{~h}$.

ing the $N$-neopentyl backbone (Scheme 13). After 1 week, the syn complexes Ru-XVa and $\mathbf{R u}-\mathbf{X V b}$ were almost completely decomposed, however, the anti-complexes Ru-XVIa and $\mathbf{R u}-\mathbf{X V I b}$ proved more resistant to decomposition and were stable for up to 10 days. Furthermore, bulkier $N$-alkyl groups tended to help stabilize the catalyst.

In terms of overall reactivity, the $N$-alkyl substituent did not play a major role in the catalyst reactivity (Scheme 13b). When less substituted olefin $\mathbf{3 2}$ was subjected to a variety of catalysts with varying $N$-alkyl substituents, no significant difference in yield was observed, however, the bulkier catalysts required slightly longer reaction times. The backbone substituents played a more significant role in reactivity, as the anti-complexes Ru-XVIa and $\mathbf{R u}-\mathbf{X V I b}$ gave higher yields than their syn-counterparts. In the presence of bulkier olefins (Scheme 13b), a slight decrease in reactivity was observed, which is attributed to unfavorable steric interactions. ${ }^{68}$

\section{Carbonyl-Olefin Metathesis}

While traditional olefin-olefin metathesis has been a powerful tool in a wide range of applications including natural product synthesis, materials and polymers, medicines, and fine chemical synthesis, a continued challenge is finding inexpensive, sustainable catalysts. Furthermore, the application of olefin-olefin metathesis often requires the prerequisite synthesis of the olefin precursors through olefination reactions that generate stoichiometric quantities of waste. An intriguing alternative that has emerged in recent years is the application of carbonyl-olefin metathesis. In 1993 Grubbs and $\mathrm{Fu}^{70}$ reported the synthesis of five-, six-, and seven-membered cycloalkenes (Scheme 14) by subjecting various olefinic ketones to Schrock's catalyst to perform the carbonyl-olefin metathesis sequence via the formation and fragmentation of intermediate oxametallacycles 59. ${ }^{70}$ 
(a) Recent developments in unsymmetrical $\mathrm{N}$-heterocyclic carbenes as catalysts in ring-closing metathesis.

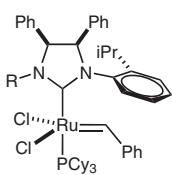

Ru-XVa $(R=C y)$ Ru-XVa $(R=C y)$
$R u-X V b(R=M e)$

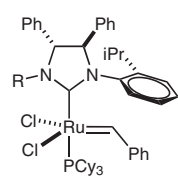

Ru-XVla $(R=C y)$
Ru-XVIb $(R=M e)$

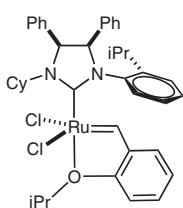

Ru-XVII

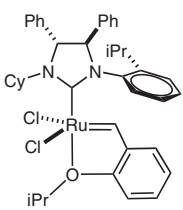

Ru-XVIII

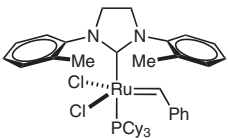

Ru-XII ( $\left.\mathrm{L}=\mathrm{PC} y_{3}\right)$

(b) Key results form kinetic profiles comparing unsymmetrical $N$-heterocyclic carbenes in the synthesis of sterically unhindered $\mathbf{3 3}$ and $\mathbf{4 6 .}$

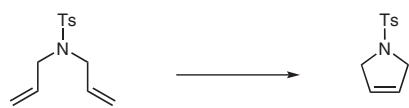

32

\begin{tabular}{|cccc|}
\hline entry & catalyst & time $(\mathrm{min})$ & $\%$ yield \\
\hline 1 & Ru-XVa & 32 & 60 \\
2 & Ru-XVb & 65 & 60 \\
3 & Ru-XVIa & 94 & 35 \\
4 & Ru-XVIb & 94 & 35 \\
5 & Ru-XVII & 60 & 94 \\
6 & Ru-XVIII & 3 & 99 \\
7 & Ru-XII & $>99$ & 27 \\
8 & HG-II & 4 & $>99$ \\
\hline
\end{tabular}<smiles>CC1=CC([N+](=O)[O-])CC(C)=C1</smiles>

45<smiles>CC1=C([N+](=O)[O-])CN([125I])C1</smiles>

46

\begin{tabular}{|cccc|}
\hline entry & catalyst & time $(\mathrm{min})$ & $\%$ yield \\
\hline 9 & Ru-XVa & 60 & 33 \\
10 & Ru-XVb & 60 & 29 \\
11 & Ru-XVIa & 60 & 64 \\
12 & Ru-XVIb & 60 & 31 \\
13 & Ru-XVII & 60 & 77 \\
14 & Ru-XVIII & 60 & 97 \\
15 & Ru-XII & 60 & 92 \\
16 & HG-II & 60 & 72 \\
\hline
\end{tabular}

Scheme 13 Ruthenium alkylidene catalysts containing unsymmetrical NHC ligands and the effects of olefinic substitution on the kinetic profiles of ruthenium catalysts ${ }^{68,69}$

However, stoichiometric quantities of Schrock's catalyst were required due to the formation of a metal-oxo species 61, which is difficult to reduce back to the active metal alkylidene.

$$
\left.\|_{0}^{+}\right\rangle_{R}
$$$$
\begin{gathered}
\begin{array}{c}
\text { Schrock's Cataly } \\
\text { (1 equiv) }
\end{array} \\
\hline \text { benzene } \\
\mathrm{rt}, 30 \mathrm{~min}
\end{gathered}
$$

58

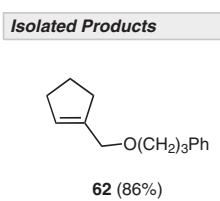

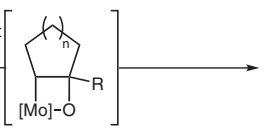

59

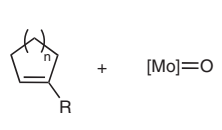

60

61

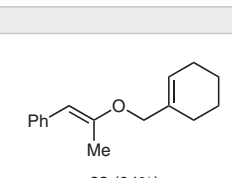

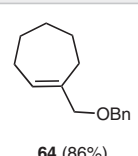

$64(86 \%)$
Scheme 14 Early examples of carbonyl-olefin metathesis applied towards the synthesis of cycloalkenes

The first reported example of carbonyl-olefin metathesis in the presence of amines came in 2009 from Zhou and Rainier. ${ }^{71}$ Their strategy focused on the formation of titanium alkylidenes. This method was used to synthesize five-, six-, and seven-membered rings through a carbonyl-olefin metathesis pathway (Scheme 15a). Mechanistic insights for this synthesis came when tosylamine $\mathbf{7 1}$ was subjected to the metathesis conditions resulting in a mixture of tetrahydropyridine 72A and acyclic enamide 72B. When the acyclic enamide was resubjected to the reaction conditions, none of the cyclic product was formed. This supports the hypothesis that the cyclic product proceeds via a carbonylolefin pathway as opposed to an olefin-olefin metathesis mechanism (Scheme 15b).

$$
\begin{aligned}
& \text { (a) Carbonyl-olefin metathesis to access benzyl fused enamines: } \\
& 65(n=0) \\
& 67(n=1) \\
& 69(n=2)
\end{aligned}
$$

(b) Carbonyl-olefin metathesis to access tetrahydropyridines and mechanistic studies:

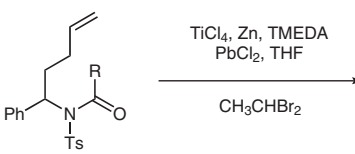

$71(\mathrm{R}=\mathrm{Me})$
$73(\mathrm{R}=\mathrm{Et})$<smiles>[R]/C(=C/C)N(C)C(CC/C=C\C)c1ccccc1</smiles>
$\begin{aligned} 72 \mathrm{R} & =\mathrm{Me}(80 \% ; \mathrm{A}: \mathrm{B}=75: 25) \\ 74 \mathrm{R} & =\mathrm{Et}(80 \% ; \mathrm{A}: \mathrm{B}=75: 25)\end{aligned}$
Scheme 15 Titanium-mediated carbonyl-olefin metathesis for the synthesis of unsaturated nitrogen heterocycles

From 2015 our group has reported the development of a Lewis acid catalyzed carbonyl-olefin metathesis reaction which proceeds via activation of the carbonyl to promote 
the formation of intermediate oxetanes (Scheme 16a). ${ }^{72}$ This approach has since been applied to a variety of systems, but amine-containing systems proved to be challenging. Under initial reaction conditions, we found that the tosyl-protected allylamines underwent the cyclization in up to $37 \%$ yield with substoichiometric quantities of the Lewis acid catalyst. ${ }^{72,74} \mathrm{Li}$ and co-workers ${ }^{73}$ found that by replacing the prenyl fragment with a styryl olefin and adding superstoichiometric amounts of allyl-TMS they could isolate the corresponding pyrrolines in up to 99\% yield (Scheme 16b); however, this method did not work as well in the synthesis of tetrahydropyridines. They hypothesized that the allyl-TMS plays a dual role under optimized reaction conditions by coordinating to the iron catalyst and promoting the formation and subsequent fragmentation of the oxetane intermediate as well as acting as a benzaldehyde scavenger.

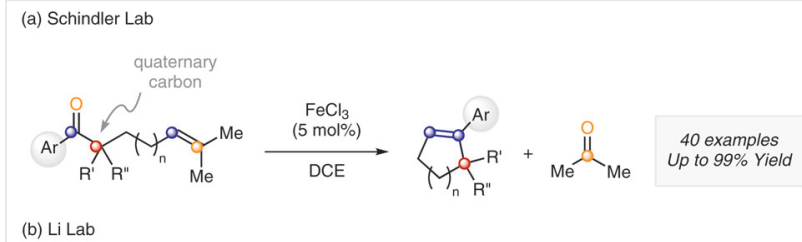

(b) Li Lab

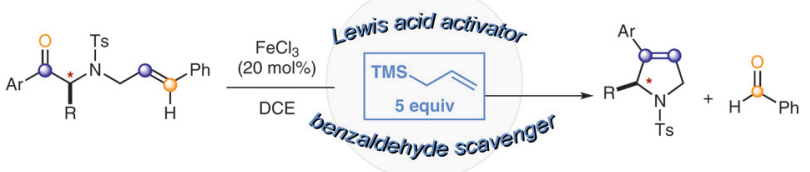

(c) Our work towards the synthesis of nitrogen heterocycles

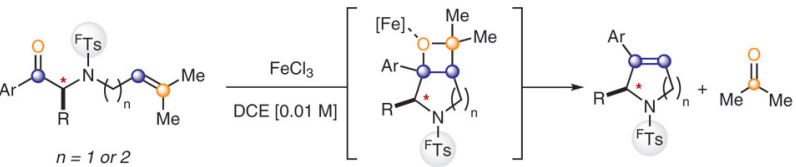

$$
\begin{aligned}
& \mathrm{F}_{\mathrm{Ts}}=4-\left(\mathrm{F}_{3} \mathrm{C}\right) \mathrm{C}_{6} \mathrm{H}_{4} \mathrm{SO}_{2}
\end{aligned}
$$

Scheme 16 (a) Initial development of an iron-mediated carbonyl-olefin metathesis reaction; (b) evaluation of allyl-TMS as an additive to promote the desired transformation; (c) recent developments towards the application of carbonyl-olefin metathesis towards the synthesis of chiral pyrrolines and tetrahydropyridines

During the course of our studies, we hypothesized that the diminished yields for nitrogen heterocycles were likely due to the Lewis basic amine acting as a competitive binding site that prevents the Lewis acid catalyst from promoting the desired transformation. ${ }^{74}$

In order to prevent the sequestration of the catalyst, we replaced the tosyl protecting group with the more electronwithdrawing 4-(trifluoromethyl)benzenesulfonyl ( ${ }^{\mathrm{F} T s}$ ) derivative $\mathbf{7 5}$ (Scheme 17a). When $\mathbf{7 5}$ was subjected to 50 $\mathrm{mol} \%$ of $\mathrm{FeCl}_{3}$, we were able to generate pyrroline $\mathbf{7 7}$ in $99 \%$ yield. Computational analyses of the two derivatives also revealed that $\mathbf{7 5 A}$ was $1.9 \mathrm{kcal} / \mathrm{mol}$ higher in energy compared to tosylamine 75B resulting in preferential binding of the Lewis acid to the carbonyl oxygen (Scheme 17b).

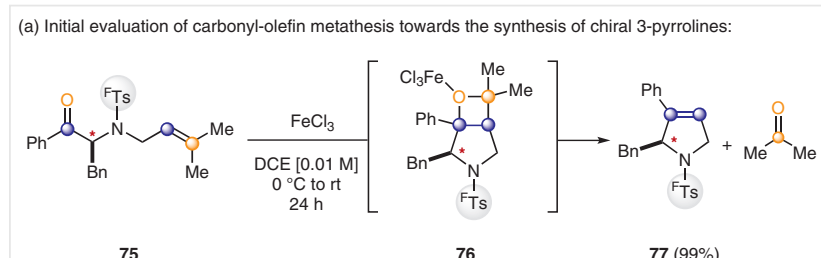

(b) Analysis of Lewis basic binding sites and catalyst reactivity:

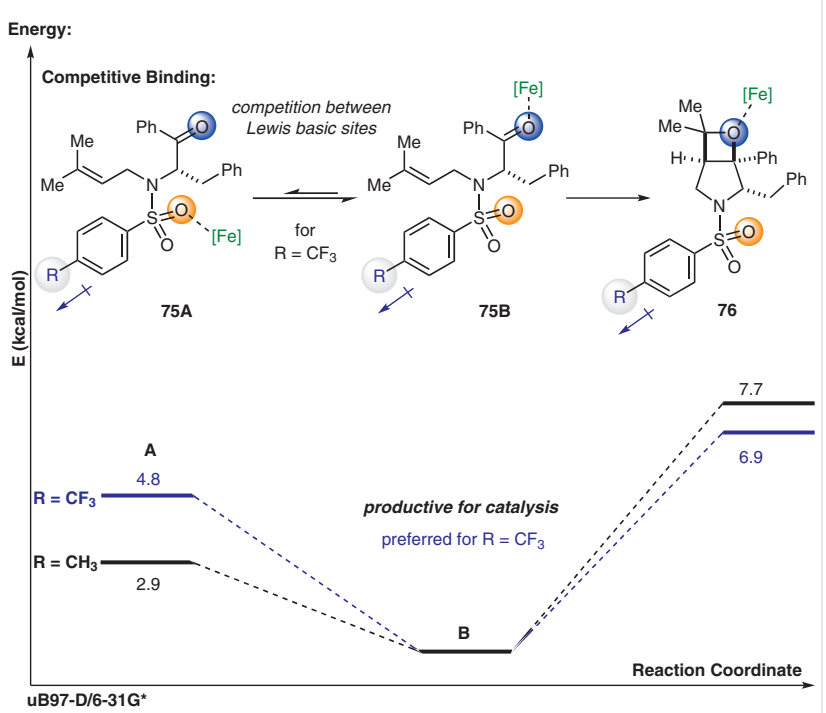

Scheme 17 Optimization of reaction conditions and computational studies into Lewis acid coordination to the Lewis basic sulfonamide versus the aryl ketone

With this strategy in hand, we were able to access a wide range of pyrrolines (Scheme 18). The reaction worked well for both electron-rich and electron-deficient aryl ketones, but the addition of more Lewis basic sites resulted in slightly lower yields. This reaction all worked well for a variety of steric motifs ranging from the unencumbered glycine derivative $\mathbf{7 8}$ to the disubstituted amino-isobutyric acid derivative $\mathbf{8 2}$. This reaction could even be applied to the sterically bulky naphthyl $\mathbf{8 6}$ in good yields. It is also interesting to note that when compared to the corresponding tosyl derivatives, the ${ }^{\mathrm{F}}$ Ts-protected substrates consistently outperformed the tosyl-protected materials by up to $30 \%$ yield. ${ }^{74}$

After applying the Lewis acid mediated carbonyl-olefin metathesis reaction towards the synthesis of pyrrolines, we set out to apply this strategy to the more challenging tetrahydropyridines derivatives (Scheme 19). ${ }^{75}$ Reaction optimization revealed that higher temperatures were required, but the reaction exhibited a similar broad substrate scope. It could be applied to sterically unencumbered substrates such as the glycine derivative $\mathbf{8 7}$ in good yields, as well as more sterically bulky systems. Furthermore, the reaction exhibited the same tolerance for electron-poor systems $\mathbf{9 3}$ and 94 as well as in the systems of heteroaromatic sub- 


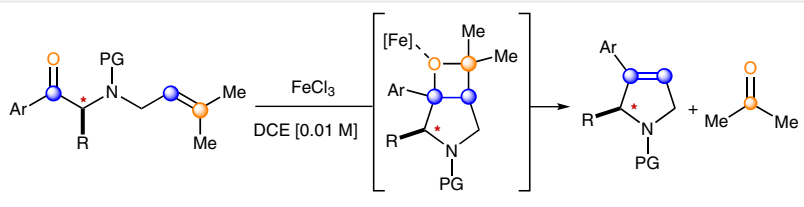

Selected Examples

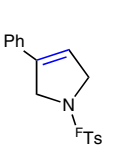

78
$50 \%$<smiles>CC(C)C1C(c2ccccc2)=CCN1P(C)(=O)c1ccccc1</smiles>

83
$32 \%$<smiles>CC1C(c2ccccc2)=CCN1[13CH3]</smiles>

79
$84 \%$<smiles>CC1C(c2cccc([N+](=O)[O-])c2)=CCN1[13CH3]</smiles>

84
$97 \%$<smiles>CCCCC(C)N1CC=C(c2ccc(Cl)cc2)C1Cc1cccs1</smiles>

81
$84 \%$

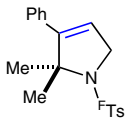

82
$92 \%$<smiles>COc1ccc(C2=CCN(C(F)(F)F)C2Cc2ccccc2)cc1</smiles>

85
$93 \%$

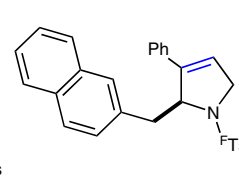

86
$87 \%$
Scheme 18 Application of the carbonyl-olefin metathesis reaction to the synthesis of chiral 3-pyrrolines. Reagents and conditions: substrate ( $0.20 \mathrm{mmol}$ ), $\mathrm{FeCl}_{3}$ ( 0.5 equiv), $0.01 \mathrm{M} \mathrm{DCE}, 0{ }^{\circ} \mathrm{C}$ for $1 \mathrm{~h}$, then rt, $24 \mathrm{~h}$.

strates 91 and 95. The reactions did exhibit a similar decrease in yield in the presence of Lewis basic sites $\mathbf{9 2}$, however we found that longer reaction times can help overcome this limitation.
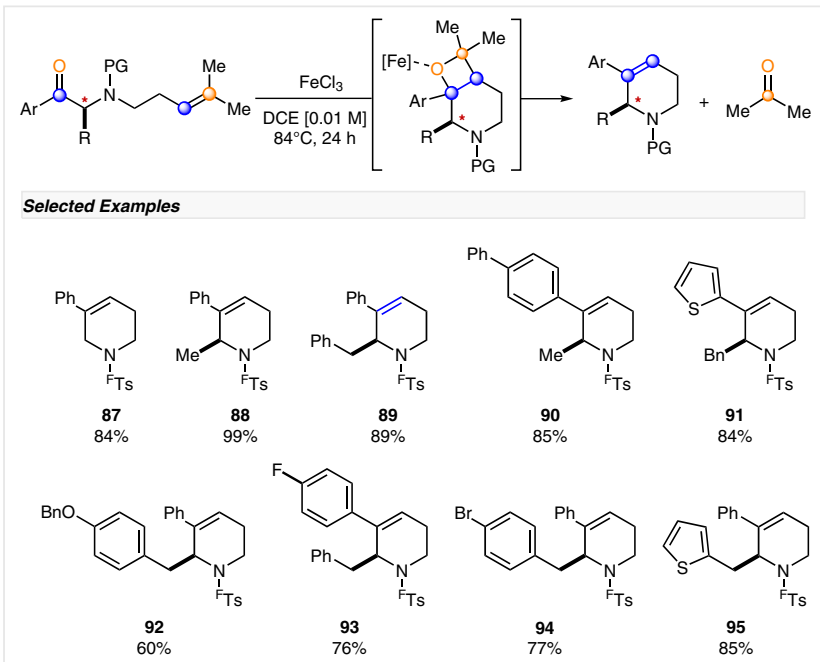

Scheme 19 Application of the carbonyl-olefin metathesis reaction to the synthesis of chiral tetrahydropyridines

\section{Conclusions}

Electron-rich amines have caused significant challenges for the application of olefin metathesis. Strategies for attenuating their Lewis basicity in order to promote desired me- tathesis reactions have enabled access to more complex ring systems including the incorporation of protecting groups and electron-withdrawing groups as well as sterically bulky substituents to prevent undesired coordination to the metal alkylidene catalysts; however, these can add undesired steps to overall synthetic strategies. Recent developments in reaction and catalyst design have enabled the application of ring-closing metathesis to more challenging nitrogen heterocycles without the need for protection or substrate alteration.

Moving forward, advances in metathesis will enable access to more complex, chiral nitrogen heterocycles under greener reaction conditions. The newly developed carbonyl-olefin metathesis reaction eliminates the need for an additional olefination step and utilizes iron as an inexpensive, earth abundant catalyst. While current carbonyl-olefin metathesis methods have been successfully applied towards the synthesis of chiral pyrrolines and tetrahydropyridines, there are many areas where this approach could prove fruitful. The application of this method to larger ring systems would be a significant advancement that would enable rapid access to bioactive molecules. Furthermore, a protecting-group-free strategy would allow for rapid access to the desired nitrogen heterocycles without requiring additional protection/deprotection steps. The application of Lewis acid catalyzed carbonyl-olefin metathesis towards the synthesis of more complex, protecting-group-free nitrogen heterocycles will mark a significant advancement in the metathesis toolkit.

\section{Funding Information}

We thank the University of Michigan Office of Research and the NIH/National Institute of General Medical Sciences (R01-GM118644) for financial support. E.J.G. thanks the National Science Foundation for a predoctoral fellowship. C.S.S. thanks the David and Lucile Packard Foundation, the Alfred P. Sloan Foundation, and the Camille and Henry Dreyfus Foundation.

\section{References}

(1) For leading references, see: (a) Naturally Occurring Pyrrolizidine Alkaloids; Rizk, A.-F. M., Ed.; CRC Press: Boca Raton, 1991. (b) Mattocks, A. R. Chemistry and Toxicology of Pyrrolizidine Alkaloids; Academic Press: London, 1986. (c) Bronner, S. M.; Im, G.-Y. J.; Garg, N. K. In Heterocycles in Natural Product Synthesis; Majumdar, K. C.; Chattopadhyay, S. K., Ed.; Wiley-VCH: Weinheim, 2011, 221. (d) Michael, J. P. Nat. Prod. Rep. 2008, 25, 139. (e) Michael, J. P. Alkaloids 2001, 55, 91. (f) Li, X.; Li, J. Mini-Rev. Med. Chem. 2010, 10, 794. (g) Vikatu, E.; Smith, D. T.; Njardarson, J. T. J. Med. Chem. 2014, 57, 10257. (h) Weintraub, P. M.; Sabol, J. S.; Kane, J. M.; Borcherding, D. R. Tetrahedron 2003, 59, 2953. (i) Mitchinson, A.; Nadin, A. J. Chem. Soc., Perkin Trans. 1 2000, 2862; and earlier reviews in this series.

(2) Iminosugars: From Synthesis to Therapeutic Applications; Compain, P.; Martin, O. R., Ed.; Wiley: Chichester, 2007. 
(3) For the therapeutics listed in this review, see: (a) Hollmann, M.; Heinemann, S. Annu. Rev. Neurosci. 1994, 17, 31. (b) Iwanami, S.; Takashima, M.; Hirata, Y.; Haseqawa, O.; Usuda, S. J. Med. Chem. 1981, 24, 1224. (c) Maring, C.; McDaniel, K.; Krueger, A.; Zhao, C.; Sun, M.; Madigan, D.; DeGoey, D.; Chen, J.-J.; Yeung, M. C.; Flosi, W.; Grampovnik, D.; Kati, W.; Klein, L.; Stewart, K.; Stoll, V.; Saldivar, S.; Montgomery, D.; Carrick, R.; Steffy, K.; Kempf, D.; Molla, A.; Kohlbrenner, W.; Kennedy, A.; Herrin, T.; Xu, Y.; Laver, W. G. Antiviral Res. 2001, 50, A76; Abstract 129. (d) For more examples, see reference $1 \mathrm{~g}$.

(4) (a) Wurz, R. P.; Fu, G. C. J. Am. Chem. Soc. 2005, 127, 12234. (b) O'Hagan, D. Nat. Prod. Rep. 2000, 17, 435.

(5) For examples, see: (a) Choi, Y. H.; Choi, J. Y.; Yange, H. Y.; Kim, Y. H. Tetrahedron: Asymmetry 2002, 13, 801. (b) Sweet, J. A.; Cavallari, J. M.; Price, W. A.; Ziller, J. W.; McGrath, D. V. Tetrahedron: Asymmetry 1997, 8, 207. (c) Fache, F.; Schulz, E.; Tommasino, M. L.; Lemaire, M. Chem. Rev. 2000, 100, 2159.

(6) For examples, see: (a) Mukaiyamma, T.; Sakito, Y.; Asami, M. Chem. Lett. 1979, 705. (b) Enders, D.; Thiebes, C. Pure Appl. Chem. 2001, 73, 573. (c) Reisman, S. E.; Doyle, A. G.; Jacobsen, E. N. J. Am. Chem. Soc. 2008, 130, 7198. (d) Dalko, P. I.; Moisan, L. Angew. Chem. Int. Ed. 2004, 43, 5138.

(7) (a) Xu, Z.; Lu, X. J. Org. Chem. 1998, 63, 5031. (b) Hodgson, D. M.; Miles, T. J.; Witherington, J. Tetrahedron 2003, 59, 9729. (c) Hong, J.; Zhang, Z.; Lei, H.; Cheng, H.; Hu, Y.; Yang, W.; Liang, Y.; Das, D.; Chen, S.-H.; Li, G. Tetrahedron Lett. 2009, 50, 2525.

(8) (a) Advances in Heterocyclic Chemistry, Vol. 115; Scriven, E. F. V.; Ramsden, C., Ed.; Academic Press: Cambridge (MA, USA), 2015, 1-354. (b) Lauder, K.; Toscani, A.; Scalacci, N.; Castagnolo, D. Chem. Rev. 2017, 117, 14091. (c) Lewis, J. C.; Bergman, R. G.; Ellman, J. A. Acc. Chem. Res. 2008, 41, 1013. (d) Schultz, D. M.; Wolfe, J. P. Synthesis 2012, 44, 351. (e) Patil, N. T.; Yamamoto, Y. Chem. Rev. 2008, 108, 3395.

(9) Asymmetric Synthesis of Nitrogen Heterocycles; Royer, J., Ed.; Wiley-VCH: Weinheim, 2009.

(10) For selected examples, see: (a) Ohno, H.; Toda, A.; Miwa, Y.; Taga, T.; Osawa, E.; Yamaoka, Y.; Fujii, N.; Ibuka, T. J. Org. Chem. 1999, 64, 2992. (b) Dieter, R. K.; Yu, H. Org. Lett. 2001, 3, 3855. (c) Billet, M.; Schoenfelder, A.; Klotz, P.; Mann, A. Tetrahedron Lett. 2002, 43, 1453. (d) Sai, M.; Matsubara, S. Org. Lett. 2011, 13, 4676. (e) Xu, T.; Mu, X.; Peng, H.; Liu, G. Angew. Chem. Int. Ed. 2011, 50, 8176. (f) Morita, N.; Krause, N. Org. Lett. 2004, 6, 4121. (g) Morita, N.; Krause, N. Eur. J. Org. Chem. 2006, 4634. (h) Kang, S.-K.; Kim, K.-J. Org. Lett. 2001, 3, 511. (i) Ma, S.; Yu, F.; Gao, W. J. Org. Chem. 2003, 68, 5943.

(11) Ohno, H.; Kadoh, Y.; Fujii, N.; Tanaka, T. Org. Lett. 2006, 8, 947.

(12) Wu, P.; Liu, H.; Tong, X. Tetrahedron Lett. 2012, 53, 4673.

(13) Hayes, C. J.; Sherlock, A. E.; Green, M. P.; Wilson, C.; Blake, A. J.; Selby, M. D.; Prodger, J. C. J. Org. Chem. 2008, 73, 2041.

(14) Tran, G.; Meier, R.; Harris, L.; Browne, D. L.; Ley, S. V. J. Org. Chem. 2012, 77, 11071

(15) (a) Boomination, S. S. K.; Hu, W.-P.; Sendi, G. P.; Wang, J. J. Adv. Synth. Catal. 2013, 355, 3570. (b) Zheng, C.; Wang, Y.; Gan, R. Org. Lett. 2015, 17, 916.

(16) Chogii, I.; Njardarson, J. T. Angew. Chem. Int. Ed. 2015, 54, 13706.

(17) Chelucci, G.; Saba, A. Angew. Chem., Int. Ed. Engl. 1995, 34, 78.

(18) Duttwyler, S.; Lu, C.; Rheingold, A. L.; Bergman, R. G.; Ellman, J. A. J. Am. Chem. Soc. 2012, 134, 4064.

(19) (a) Beceño, C.; Krappitz, T.; Raabe, G.; Enders, D. Synthesis 2015, 47, 38813. (b) He, L.; Laurent, G.; Retailleau, P.; Folleas, B.; Brayer, J.-L.; Masson, G. Angew. Chem. Int. Ed. 2013, 52, 11088. (c) Tambar, U. K.; Lee, S. K.; Leighton, J. L. J. Am. Chem. Soc. 2010 , 132,10249 .
(20) de la Pradilla, R. F.; Simal, C.; Bates, R. H.; Viso, A.; Infantes, L. Org. Lett. 2013, 15, 4936.

(21) (a) Zhu, X. F.; Lan, J.; Kwon, O. J. Am. Chem. Soc. 2003, 125, 4716. (b) Zhou, L.; Yuan, C.; Zeng, Y.; Liu, H.; Wang, C.; Gao, X.; Wang, Q.; Zhang, C.; Guo, H. Chem. Sci. 2018, 9, 1831.

(22) For selected examples, see: (a)Wang, Z.; Xu, H.; Su, Q.; Hu, P.; Shao, P.-L.; He, Y.; Lu, Y. Org. Lett. 2017, 19, 3111. (b) Hu, P.; Hu, J.; Jiao, J.; Tong, X. Angew. Chem. Int. Ed. 2013, 52, 5319. (c) Rutjes, F. P. J. T.; Tjen, K. C. M. F.; Wolf, L. B.; Karstens, W. F. J.; Schoemaker, H. E.; Hiemstra, H. Org. Lett. 1999, 1, 717. (d) Inuki, S.; Iwata, A.; Oishi, S.; Fujii, N.; Ohno, H. J. Org. Chem. 2011, 76, 2072. (e) Ohno, H.; Mizutani, T.; Kadoh, Y.; Aso, A.; Miyamura, K.; Fujii, N.; Tanaka, T. J. Org. Chem. 2007, 72, 4378. (f) Inkui, S.; Oishi, S.; Fujii, N.; Ohno, H. Org. Lett. 2008, 10, 5239.

(23) For examples, see: (a) Donohoe, T. J.; Guyo, P. M.; Helliwell, M. Tetrahedron Lett. 1999, 40, 435. (b) Schafer, A.; Schafer, B. Tetrahedron 1999, 55, 12309. (c) Donohoe, T. J.; Thomas, R. E. Chem. Rec. 2007, 7, 180. (d) Wu, J.; Tang, W.; Pettman, A.; Xiao, J. Adv. Synth. Catal. 2013, 355, 35.

(24) For reviews, see: (a) Blechert, S.; Schuster, M. Angew. Chem., Int. Ed. Engl. 1997, 36, 2036. (b) Montgomery, T. P.; Johns, A. M.; Grubbs, R. H. Catalysts 2017, 6, 87. (c) Ogba, O. M.; Warner, N. C.; O'Leary, D. J.; Grubbs, R. H. Chem. Soc. Rev. 2018, 47, 4510. (d) Deiters, A.; Martin, S. F. Chem. Rev. 2004, 104, 2199.

(25) (a) Fu, G. C.; Grubbs, R. H. J. Am. Chem. Soc. 1992, 114, 5426. (b) Fu, G. C.; Grubbs, R. H. J. Am. Chem. Soc. 1992, 114, 7324.

(26) (a) Ulman, M.; Grubbs, R. H. J. Org. Chem. 1999, 64, 7202. (b) Yee, N. K.; Farina, V.; Houpis, I. N.; Haddad, N.; Frutos, R. P.; Gallou, F.; Wang, X.-j.; Wei, X.; Simpson, R. D.; Feng, X.; Fuchs, V.; Xu, Y.; Tan, J.; Zhang, L.; Xu, J.; Smith-Keenan, L. L.; Vitous, J.; Ridges, M. D.; Spinelli, E. M.; Johnson, M. J. Org. Chem. 2006, 71, 7133. (c) Hong, S. H.; Wenzel, A. G.; Salguero, T. T.; Day, M. W.; Grubbs, R. H. J. Am. Chem. Soc. 2007, 129, 7961. (d) Manzini, S.; Poater, A.; Nelson, D. J.; Cavallo, L.; Slawin, A. M. Z.; Nolan, S. P. Angew. Chem. Int. Ed. 2014, 53, 8995. (e) Wilson, G. O.; Porter, K. A.; Weissman, H.; White, S. R.; Sottos, N. R.; Moore, J. S. Adv. Synth. Catal. 2009, 351, 1817. (f) Lummiss, J. A. M.; Ireland, B. J.; Sommers, J. M.; Fogg, D. E. ChemCatChem 2014, 6, 459. (g) Ireland, B. J.; Dobigny, B. T.; Fogg, D. E. ACS Catal. 2015, 5, 4690. (h) Fu, G. C.; Nguyen, S. T.; Grubbs, R. H. J. Am. Chem. Soc. 1993, 115, 9856.

(27) (a) Compain, P. Adv. Synth. Catal. 2007, 349, 1829. (b) Compain, P.; Hazelard, D. Top. Heterocycl. Chem. 2017, 47, 111. (c) Philips, A. J.; Abell, A. D. Aldrichchim. Acta. 1999, 32, 75. (d) Vernall, A. J.; Abell, A. D. Aldrichchim. Acta. 2003, 36, 93. (e) Felpin, F.-X.; Lebreton, J. Eur. J. Org. Chem. 2003, 3693. (f) Deiters, A.; Martin, S. F. Chem. Rev. 2004, 104, 2199. (g) Chattopadhyay, S. K.; Karmakar, S.; Majumdar, K. C.; Rahaman, H.; Roy, B. Tetrahedron 2007, 63, 3919.

(28) (a) Scholl, M.; Ding, S.; Lee, C. W.; Grubbs, R. H. Org. Lett. 1999, 1, 953. (b) Trnka, T. M.; Morgan, J. P.; Sanford, M. S.; Wilhelm, T. E.; School, M.; Choi, T. L.; Ding, S.; Day, M. W.; Grubbs, R. H. J. Am. Chem. Soc. 2003, 125, 2546.

(29) Zaidi, K. Pharmacopeial Forum 2008, 34, 1345.

(30) Kuhn, K. M.; Champagne, T. M.; Hong, S. H.; Wei, W.-H.; Nickel, A.; Lee, C. W.; Virgil, S. C.; Grubbs, R. H.; Pederson, R. L. Org. Lett. 2010, 12,984

(31) (a) Chao, W.; Weinreb, S. M. Org. Lett. 2003, 5, 2505. (b) Chao, W.; Meketa, M. L.; Weinreb, S. M. Synthesis 2004, 2058.

(32) For reviews of metal-catalyzed cross-couplings, see: (a) MetalCatalyzed Cross-Coupling Reactions; de Meijere, A.; Diederich, F., Ed.; Wiley-VCH: Weinheim, 2004. (b) Cross-Coupling Reactions: A Practical Guide, In Topics in Current Chemistry, Vol. 219; 
Miyaura, N., Ed.; Springer Verlag: New York, 2002. (c) Handbook of Organopalladium Chemistry for Organic Synthesis; Negishi, E.i., Ed.; Wiley-Interscience: New York, 2002.

(33) Gatti, M.; Drinkel, E.; Wu, L.; Pusteria, I.; Gaggia, F.; Dorta, R. J. Am. Chem. Soc. 2010, 132, 15179.

(34) (a) Fürstner, A.; Leitner, A. Angew. Chem. Int. Ed. 2003, 42, 308. (b) Fürstner, A.; Grabowski, J.; Lehmann, C. W. J. Org. Chem. 1999, 64, 8275. (c) Scheiper, B.; Glorius, F.; Leitner, A.; Fürstner, A. Proc. Natl. Acad. Sci. U.S.A. 2004, 101, 11960. (d) Edwards, A. S.; Wybrow, R. A.; Johnstone, C.; Adams, H.; Harrity, J. P. Chem. Commun. 2002, 1542. (e) Gracias, V.; Gasiecki, A. F.; Moor, J. D.; Akritopoulou-Zanze, I.; Djuric, S. W. Tetrahedron Lett. 2006, 47, 8977. (f) Prusov, E.; Maier, M. E. Tetrahedron 2007, 63, 10486. (g) Wright, D. L.; Schulte, J. P. II.; Page, M. A. Org. Lett. 2000, 2, 1847.

(35) Yang, Q.; Xiao, W. J.; Yu, Z. Org. Lett. 2005, 7, 871.

(36) Woodward, C. P.; Spiccia, N. D.; Jackson, W. R.; Robinson, A. J. Chem. Commun. 2011, 47, 779.

(37) (a) Boger, D. L.; Turnbull, P. J. Org. Chem. 1997, 62, 5849. (b) Marten, S. F.; Liao, Y. S.; Wong, Y. L.; Reing, T. Tetrahedron Lett. 1994, 35, 691. (c) Pilli, R. A.; de Oliveira, M. D. C. F. Nat. Prod. Rep. 2000, 17, 117. (d) Sakai, R.; Higa, T. J. Am. Chem. Soc. 1986, 108, 6404. (e) Wipf, P.; Spencer, S. R. J. Am. Chem. Soc. 2005, 127, 225.

(38) Teichert, J. F.; Zhang, S.; van Zijl, A. W.; Slaa, J. W.; Minnaard, A. J.; Feringa, B. L. Org. Lett. 2010, 12, 4658.

(39) (a) Garber, S. B.; Kingsbury, J. S.; Gray, B. L.; Hoveyda, A. H.J. Am. Chem. Soc. 2000, 122, 8168. (b) Gessler, S.; Randl, S.; Blechert, S. Tetrahedron Lett. 2000, 41, 9973.

(40) (a) Grela, K.; Harutyunyan, S.; Michrowska, A. Angew. Chem. Int. Ed. 2002, 41, 4038. (b) Grela, K.; Kim, M. Eur. J. Org. Chem. 2003, 963. (c) Van Veldhuizen, J. J.; Gillingham, D. G.; Garber, S. B.; Katoaka, O.; Hoveyda, A. H. J. Am. Chem. Soc. 2003, 125, 12502.

(41) Tzur, E.; Szadkowska, A.; Ben-Asuly, A.; Makal, A.; Goldberg, I.; Wozniak, K.; Grela, K.; Lemcoff, N. G. Chem. Eur. J. 2010, 16, 8726.

(42) (a) Schmidt, B. Angew. Chem. Int. Ed. 2003, 42, 4996. (b) Yamamoto, Y.; Nakagai, Y.; Ohkoshi, N.; Itoh, K. J. Am. Chem. Soc. 2001, 123, 6372. (c) Hong, S.; Sanders, D. P.; Lee, C. W.; Grubbs, R. H. J. Am. Chem. Soc. 2005, 127, 17160.

(43) (a) Slugovc, C.; Perner, B.; Stelzer, F.; Mereiter, K. Organometallics 2004, 23, 3622. (b) Burtscher, D.; Perner, B.; Mereiter, K.; Slugovc, C. J. Organomet. Chem. 2006, 691, 5423.

(44) (a) Ung, T.; Heijl, A.; Grubbs, R. H.; Schrodi, Y. Organometallics 2004, 23, 5399. (b) Slugovc, C.; Burtscher, D.; Stelzer, F.; Mereiter, K. Organometallics 2005, 24, 2255. (c) Szadkowska, A.; Gstrein, X.; Burtscher, D.; Jarzembska, K.; Wozniak, K.; Slugovc, C.; Grela, K. Organometallics 2010, 29, 117.

(45) (a) Szadkowska, A.; Makal, A.; Wozniak, K.; Kadyrov, R.; Grela, K. Organometallics 2009, 28, 2693. (b) Kost, T.; Sigalov, M.; Goldberg, I.; Ben-Asuly, A.; Lemcoff, N. G. J. Organomet. Chem. 2008, 693, 2200. (c) Ben-Asuly, A.; Tzur, E.; Diesendruck, C. E.; Sigalov, M.; Goldberg, I.; Lemcoff, N. G. Organometallics 2008, 27, 811. (d) Ben-Asuly, A.; Tzur, E.; Diesendruck, C. E.; Sigalov, M.; Goldberg, I.; Lemcoff, N. G. Organometallics 2009, 28, 4652.

(46) Diesendruck, C. E.; Tzur, E.; Ben-Asuly, A.; Goldberg, I.; Straub, B. F.; Lemcoff, N. G. Inorg. Chem. 2009, 48, 10819.

(47) Lexer, C.; Burtscher, D.; Perner, B.; Tzur, E.; Lemcoff, N. G.; Slugovc, C. J. Organomet. Chem. 2011, 696, 2466.

(48) Kuethe, J.; Zhong, Y.-L.; Yasuda, N.; Beutner, G.; Linn, K.; Kim, M.; Marcune, B.; Dreher, S. D.; Humphrey, G.; Pei, T. Org. Lett. 2013, 15, 4174.
(49) Williams, M. J.; Kong, J.; Chung, C. K.; Brunskill, A.; Campeau, L.C.; McLaughlin, M. Org. Lett. 2016, 18, 1952.

(50) Kajetanowicz, A.; Milewski, M.; Rogińska, J.; Gajda, R.; Woźniak, K. Eur. J. Org. Chem. 2017, 626.

(51) (a) Trnka, T. M.; Grubbs, R. H. Acc. Chem. Res. 2001, 34, 18. (b) Samojlowicz, C.; Bieniek, M.; Grela, K. Chem. Rev. 2009, 109, 3708.

(52) Vougioukalakis, G. C.; Grubbs, R. H. Chem. Rev. 2010, 110, 1746.

(53) (a) Love, J. A.; Morgan, J. P.; Trnka, T. M.; Grubbs, R. H. Angew. Chem. Int. Ed. 2002, 41, 4035. (b) Clavier, H.; Petersen, J. L.; Nolan, S. P. J. Organomet. Chem. 2006, 691, 54444.

(54) (a) Boeda, F.; Clavier, H.; Nolan, S. P. Chem. Commun. 2008, 2726. (b) Clavier, H.; Urbina-Blanco, C. A.; Nolan, S. P. Organometallics 2009, 28, 2848. (c) Bantriel, X.; Schmid, T. E.; Randall, R. A. M.; Slawin, A. M. Z.; Xazin, C. S. J. Chem. Commun. 2010, 46, 7115. (d) Clavier, H.; Nolan, S. P. Chem. Eur. J. 2007, 13, 8029. (e) Bieniek, M.; Michrowska, A.; Usanov, D. L.; Grela, K. Chem. Eur. J. 2008, 14, 806.

(55) Urbina-Blanco, C. A.; Leitgeb, A.; Slugovc, C.; Bantreil, X.; Clavier, H.; Slawin, A. M. Z.; Nolan, S. P. Chem. Eur. J. 2011, 17, 5045.

(56) Manzini, S.; Urbina Blanco, C. A.; Slawin, A. M. Z.; Nolan, S. P. Organometallics 2012, 31, 6514.

(57) (a) Vehlow, K.; Gessler, S.; Blechert, S. Angew. Chem. Int. Ed. 2007, 46, 8082. (b) Hong, S. H.; Chlenov, A.; Day, M. W.; Grubbs, R. H. Angew. Chem. Int. Ed. 2007, 46, 5184.

(58) (a) Chung, C. K.; Grubbs, R. H. Org. Lett. 2008, 10, 2693. (b) Kuhn, K. M.; Bourg, J.-B.; Chung, C. K.; Virgil, S. C.; Grubbs, R. H. J. Am. Chem. Soc. 2009, 131, 5313. (c) Grisi, F.; Mariconda, A.; Costabile, C.; Bertolasi, V.; Longo, P. Organometallics 2009, 28, 4988. (d) Costabile, C.; Mariconda, A.; Cavallo, L.; Longo, P.; Bertolasi, V.; Ragone, F.; Grisi, F. Chem. Eur. J. 2011, 17, 8618.

(59) Torborg, C.; Szczepaniak, G.; Zielinski, A.; Malinska, M.; Wozniak, K.; Grela, K. Chem. Commun. 2013, 49, 3188.

(60) (a) Furstner, A.; Liebl, M.; Lehmann, C. W.; Picquet, M.; Kunz, R.; Bruneau, C.; Touchard, D.; Dixneuf, P. H. Chem. Eur. J. 2000, 6, 1847. (b) Miyaki, Y.; Onishi, T.; Kurosawa, H. Inorg. Chim. Acta 2000, 300-302, 369. (c) Wang, D.; Wurst, K.; Knolle, W.; Decker, U.; Prager, L.; Naumov, S.; Buchmeiser, M. R. Angew. Chem. Int. Ed. 2008, 47, 3267. (d) Volland, M. A. O.; Hansen, S. M.; Rominger, F.; Hofmann, P. Organometallics 2004, 23, 800. (e) Zirngast, M.; Pump, E.; Leitgeb, A.; Albering, J. H.; Slugovc, C. Chem. Commun. 2011, 47, 2261.

(61) (a) Songis, O.; Slawin, A. M. Z.; Cazin, C. S. J. Chem. Commun. 2012, 48, 1266. (b) Volland, M. A. O.; Hansen, S. M.; Rominger, F.; Hofmann, P. Organometallics 2004, 23, 800.

(62) Olefin Metathesis: Theory and Practice; Grela, K., Ed.; WileyVCH: Weinheim, 2014.

(63) For examples, see: Alexander, J. B.; La, D. S.; Cefalo, D. R.; Hoveyda, A. H.; Schrock, R. R. J. Am. Chem. Soc. 1998, 120, 4041.

(64) (a) La, D. S.; Alexander, J. B.; Cefalo, D. R.; Graf, D. D.; Hoveyda, A. H.; Schrock, R. R. J. Am. Chem. Soc. 1998, 120, 9720. (b) Zhu, S. S.; Cefalo, D. R.; La, D. S.; Jamieson, J. Y.; Davis, W. M.; Hoveyda, A. H.; Schrock, R. R. J. Am. Chem. Soc. 1999, 121, 8251. (c) Cefalo, D. R.; Kiely, A. F.; Wuchrer, M.; Jamieson, J. Y.; Schrock, R. R.; Hoveyda, A. H. J. Am. Chem. Soc. 2001, 123, 3139. (d) Keily, A. F.; Jernelius, J. A.; Schrock, R. R.; Hoveyda, A. H. J. Am. Chem. Soc. 2002, 124, 2868. (e) Sattely, E. S.; Cortez, A.; Moebius, D. C.; Schrock, R. R.; Hoveyda, A. H. J. Am. Chem. Soc. 2005, 127, 8526.

(65) Dolman, S. J.; Satterly, E. S.; Hoveyda, A. H.; Schrock, R. R. J. Am. Chem. Soc. 2002, 124, 6991.

(66) Hartung, J.; Dornan, P. K.; Grubbs, R. H. J. Am. Chem. Soc. 2014, $136,13029$.

(67) Costabile, C.; Cavallo, L. J. Am. Chem. Soc. 2004, 126, 9592. 
(68) Paradiso, V.; Bertolasi, V.; Costabile, C.; Caruso, T.; Dąbrowski, M.; Grela, K.; Grisi, F. Organometallics 2017, 36, 3692.

(69) Paradiso, V.; Bertolasi, V.; Costabile, C.; Grisi, F. Dalton Trans. 2016, 45, 561.

(70) Fu, G. C.; Grubbs, R. H. J. Am. Chem. Soc. 1993, 115, 3800.

(71) Zhou, J.; Rainier, J. D. Org. Lett. 2009, 11, 3774.

(72) (a) This work was first reported as Ludwig, J. R.; Gianino, J. B.; Schindler, C., Abstracts of Papers, 250th National Meeting of the American Chemical Society, Boston MA, Aug 16-20, 2015; American Chemical Society: Washington DC, 2015, ORGN-388. Nitrogen-containing substrates were disclosed as challenging for Lewis acid catalyzed carbonyl-olefin metathesis proceeding in 37\% yield. (b) Ludwig, J. R.; Zimmerman, P. M.; Gianino, J. B.; Schindler, C. S. Nature (London) 2016, 533, 374. (c) Ludwig, J. R.; Phan, S.; McAtee, C. C.; Zimmerman, P. M.; Devery, J. J. III.; Schindler, C. S. J. Am. Chem. Soc. 2017, 139, 10832.

(73) Ma, L.; Li, W.; Xi, H.; Bai, X.; Ma, E.; Yan, X.; Li, Z. Angew. Chem. Int. Ed. 2016, 55, 10410.

(74) Groso, E. J.; Golonka, A. N.; Harding, R. A.; Alexander, B. W.; Sodano, T. M.; Schindler, C. S. ACS Catal. 2018, 8, 2006.

(75) Groso E. J., Schindler C. S.; Org. Lett.; manuscript in revision. 